\title{
C@PA: Computer-Aided Pattern Analysis to Predict Multitarget ABC Transporter Inhibitors
}

\author{
Vigneshwaran Namasivayam, Katja Silbermann, Michael Wiese, Jens Pahnke, and Sven Marcel Stefan*
}

Cite This: J. Med. Chem. 2021, 64, 3350-3366

Read Online

ABSTRACT: Based on literature reports of the last two decades, a computer-aided pattern analysis (C@PA) was implemented for the discovery of novel multitarget $\mathrm{ABCB} 1$ (P-gp), $\mathrm{ABCC} 1$ (MRP1), and ABCG2 (BCRP) inhibitors. C@PA included basic scaffold identification, substructure search and statistical distribution, as well as novel scaffold extraction to screen a large virtual compound library. Over 45,000 putative and novel broad-spectrum ABC transporter inhibitors were identified, from which 23 were purchased for biological evaluation. Our investigations revealed five novel lead molecules as triple $\mathrm{ABCB} 1, \mathrm{ABCC} 1$, and $\mathrm{ABCG} 2$ inhibitors. $\mathrm{C} @ \mathrm{PA}$ is the very first successful computational approach for the discovery of promiscuous $\mathrm{ABC}$ transporter inhibitors.

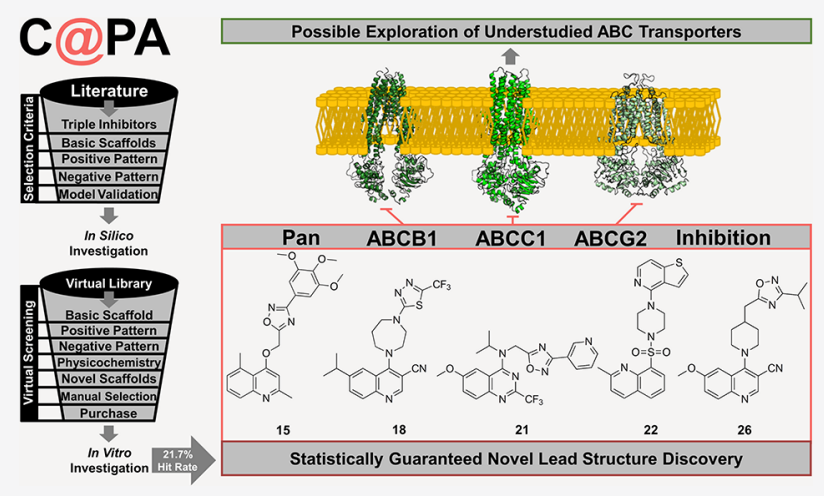

\section{INTRODUCTION}

Expression of adenosine triphosphate-(ATP)-binding cassette $(\mathrm{ABC})$ transporters in multidrug-resistant cancer remains a huge obstacle in cancer chemotherapy. Many of the $49 \mathrm{ABC}$ transporters confer resistance to structurally and functionally diverse antineoplastic agents, ${ }^{1}$ leading to the multidrug resistance (MDR) phenotype. However, small-molecule inhibitors to target $\mathrm{ABC}$ transporters are only known for a fraction of these 49 transporters. Amongst these are the three well-studied transporters ABCB1 (P-glycoprotein, P-gp), $\mathrm{ABCC} 1$ (multidrug resistance-associated protein 1, MRP1), and ABCG2 (breast cancer resistance protein, BCRP), for which a bunch of potent (and mostly specific) small-molecule inhibitors has been generated over the last four decades. ${ }^{2-4}$ Unfortunately, clinical studies approaching one single transporter with selective and highly potent agents have mostly failed. ${ }^{5-7}$ Two concluding postulations emerged very recently: (i) $\mathrm{ABC}$ transporters have a differing (individual) substrate range, which increases cross-resistance in case of their coexpression. ${ }^{6,8}$ These individual substrate ranges combined cover almost the whole range of today's applied antineoplastic agents; $^{5-8}$ (ii) $\mathrm{ABC}$ transporters have also an overlapping (collective) substrate range, enabling them to compensate for the selective inhibition and/or downregulation of their functional counterpart(s). These collective substrate ranges account for a regulatory dependency of $\mathrm{ABC}$ transporter expression in terms of a triggered upregulation. ${ }^{6,8}$ Both simultaneous overexpression of $\mathrm{ABC}$ transporters ${ }^{9,10}$ and compensation $^{11-13}$ have already been documented in the literature. This ultimately leads to maintaining, extending, and/ or shifting of the resistance profile of multidrug-resistant cancer. ${ }^{6}$ Hence, multitarget $\mathrm{ABC}$ transporter inhibition might be a novel and promising approach to treat multidrug-resistant cancer. However, the simultaneous targeting of $\mathrm{ABCB} 1$, $A B C C 1$, and $A B C G 2$ has only very recently been emphasized. $^{6,14-17}$ The term broad-spectrum inhibition itself goes back to mid-2000s. ${ }^{18}$ Since then, it was only infrequently acknowledged $^{19-22}$ and has only been addressed properly within the last couple of years. ${ }^{6,14-17,23,24}$

Less than 1200 compounds have been evaluated in vitro for $\mathrm{ABCB} 1, \mathrm{ABCC} 1$, and $\mathrm{ABCG} 2$ inhibition, of which less than 140 can be considered as broad-spectrum inhibitors. While around 50 compounds exerted their $\mathrm{ABC}$ transporter inhibiting property below $10 \mu \mathrm{M}$ for each transporter, ${ }^{14-17,21,23,25-42}$ only 22 compounds had activities below 5 $\mu \mathrm{M}^{14,15,21,23,25,26,28,32,34,37-39}$ Amongst the most potent triple $\mathrm{ABCB} 1, \mathrm{ABCC} 1$, and $\mathrm{ACBG} 2$ inhibitors are 4-anilinopyrimidine $26(1),{ }^{14}$ the tariquidar-related derivative $40(2),{ }^{23}$ the amino aryl ester derivative $(S)-9(3),{ }^{26}$ pyrrolopyrimidine 55 $(4),{ }^{17}$ indolopyrimidine $69(5),{ }^{17}$ the 2,4 -substituted quinazoline derivative $52(6),{ }^{28}$ 4-anilinoquinoline $29(7),{ }^{29}$ thienopyridine $6 \mathrm{r}(8),{ }^{32}$ benzoflavone $16(9),{ }^{34}$ and the tetrahydroisoquinoline derivative MC18 (10) $)^{21,39}$ (Figure 1).

Computational approaches with respect to $\mathrm{ABC}$ transporter inhibition have been undertaken ${ }^{43,44}$ mostly focusing on

Received: December 20, 2020

Published: March 16, 2021 
<smiles>N#Cc1ccc(Nc2cc(Nc3ccc(O)cc3)nc(-c3ccccc3)n2)cc1</smiles>

4-anilinopyrimidine 26 (1) Silbermann et al. 2021

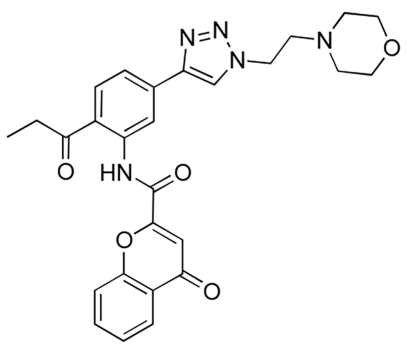

tariquidar-related derivative 40 (2) Antoni et al. 2021

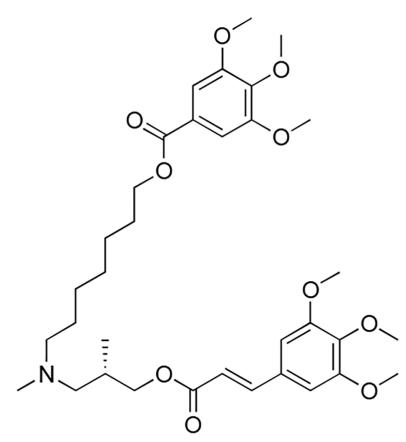

amino aryl ester derivative $(S)$-9 (3) Teodori et al. 2019<smiles>N#Cc1cn(CCCc2ccccc2)c2c(N3CCN(CCc4c[nH]c5ccccc45)CC3)ncnc12</smiles>

pyrrolopyrimidine 55 (4) Stefan et al. 2017<smiles>c1ccc(CCN2CCN(c3ncnc4c3[nH]c3ccccc34)CC2)cc1</smiles>

indolopyrimidine 69 (5) Stefan et al. 2017<smiles>COc1ccc(-c2nc(Nc3ccc(OC)c(OC)c3)c3ccccc3n2)cc1</smiles>

2,4-substituted quinazoline derivative 52 (6) Krapf et al. 2017

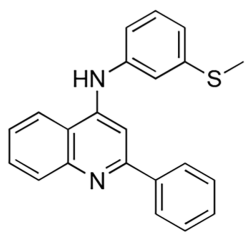

4-anilinoquinoline 29 (7) Krapf et al. 2016<smiles>COCCOC(=O)c1c(C)nc2sc(C(=O)c3ccc(OC)cc3)c(N)c2c1-c1cc(OC)c(OC)c(OC)c1</smiles><smiles>COc1ccc(-c2cc(=O)c3ccc4ccccc4c3o2)cc1OC</smiles>

Juvale et al. 2013<smiles>COc1cc2c(cc1OC)CN(CC/C=C1\CCCc3c(OC)cccc31)CC2</smiles>

tetrahydroisoquinoline derivative $\mathrm{MC} 18$ (10) Colabufo et al. 2008-2009

Figure 1. Depiction of the most potent triple $A B C B 1, A B C C 1$, and ABCG2 inhibitors derived by HTS and synthesis approaches: 4anilinopyrimidine $26(\mathbf{1})$ as reported by Silbermann et al. in $2021 ;^{14}$ the tariquidar-related derivative $40(2)$ as reported by Antoni et al. in 2021 ; $^{23}$ the amino aryl ester derivative $(S)-9$ (3) as reported by Teodori et al. in $2019 ;^{26}$ pyrrolopyrimidine $55(4)$ and indolopyrimidine 71 (5) as reported by Stefan et al. in $2017 ;{ }^{17}$ the 2,4-substituted quinazoline derivative $52(6)$ as reported by Krapf et al. in 2017; 28 -anilinoquinoline 29 (7) as reported by Krapf et al. in $2016 ;^{29}$ thienopyridine $6 \mathrm{r}(8)$ as reported by Krauze et al. in 2014; ${ }^{32}$ benzoflavone 16 (9) as reported by Juvale et al. in $2013 ;^{34}$ and the tetrahydroisoquinoline derivative MC18 (10) as reported by Colabufo et al. in $2008^{39}$ and $2009 .^{21}$

selective inhibition of $\mathrm{ABCB} 1,{ }^{45,46} \mathrm{ABCC} 1,{ }^{16}$ or $\mathrm{ABCG} 2^{47}$ individually. No approach took inhibitors of more than one $\mathrm{ABC}$ transport protein into account. However, this would revolutionize our understanding of $\mathrm{ABC}$ transporters as this could address two major aspects: (i) identification of structural requirements for a simultaneous targeting of $\mathrm{ABCB} 1, \mathrm{ABCC} 1$, and $A B C G 2$ and, vice versa, identification of structural features for selective inhibition of one of these transporters; and (ii) potentially deciphering common structural features to address other $\mathrm{ABC}$ transporters that are not able to be targeted by small-molecules until now. In order to give way for the discovery and development of novel broad-spectrum $A B C$ transporter modulators, we implemented C@PA, a computeraided pattern analysis, which is presented in this work.

\section{RESULTS}

Computational Analysis. Compilation of Data Set and Classification of Compounds. As a first step, 93 reports between 2004 and 2021 were collected in which the evaluation of small-molecule inhibitors of ABCB1, ABCC1, and ABCG2 was described. Reports that did not include biological investigations on all three transporters were not considered, as a subsequent classification of the compounds would fail due to missing activity value(s). The half-maximal inhibition concentration $\left(\mathrm{IC}_{50}\right)$ values of the compounds were considered as the major indicator of direct inhibition. Other biological data that was not based on tracing of (immediate) $\mathrm{ABC}$ transporter-mediated transport (e.g., by a fluorescence dye or a radionuclide) was not taken into account as these 
surrogates [e.g., the half-maximal reversal concentrations $\left(\mathrm{EC}_{50}\right)$ obtained in MDR reversal assays] and their observed effects (e.g., the shift in toxicity of a co-administered antineoplastic agent) may not be (directly) linked to inhibition of transport activity alone but also to unspecific, non-ABC transporter-related targets. The $\mathrm{IC}_{50}$ values were either extracted from tables as reported in the respective publication or estimated from relative inhibition $\left(\mathrm{I}_{\text {rel }}\right)$ values compared to the maximal inhibition exerted by a standard inhibitor $\left(\mathrm{I}_{\max }\right)$. In the latter case, the $\mathrm{IC}_{50}$ was categorized into $<10 \mu \mathrm{M}$ ("active") or $\geq 10 \mu \mathrm{M}$ ("inactive"). The dataset including compound names and SMILES codes, inhibitory activity values against $\mathrm{ABCB} 1, \mathrm{ABCC} 1$, and $\mathrm{ABCG} 2$, used cell lines and testing systems, as well as the links to the corresponding literature can be found in Supplementary Table 1 .

In total, 1049 compounds were identified, which have been evaluated at least once regarding $\mathrm{ABCB} 1, \mathrm{ABCC} 1$, and $A B C G 2$. In case a compound has been evaluated in more than one assay, the mean of the reported $\mathrm{IC}_{50}$ values was taken for further analysis. In case one compound was evaluated with a definite number (e.g., 9.6 $\mu \mathrm{M})$ and an estimation (e.g., $>25$ $\mu \mathrm{M}$ ), the definite number was always given priority, while the estimated value was not considered. The same accounts for a compound that was classified as "inactive" in one assay and associated with a definite $\mathrm{IC}_{50}$ value in another assay. If a range was given $($ e.g., $4-5 \mu \mathrm{M})$, the mean has been taken for further analysis (e.g., $4.5 \mu \mathrm{M}$ ). The dataset for ongoing analysis, including compound names and SMILES codes, can be found in Supplementary Table 2.

In a next step, the compounds of Supplementary Table 2 were categorized into "active" [1 ("one"); $\mathrm{IC}_{50}$ value $<10 \mu \mathrm{M}$ ] and "inactive" [0 ("zero"); $\mathrm{IC}_{50}$ values $\geq 10 \mu \mathrm{M}$ ]. As a result, 256 compounds were found to be active against $\mathrm{ABCB} 1$, while 793 were inactive. Concerning $A B C C 1,147$ were active, while 902 were found to be inactive. Finally, regarding ABCG2, 629 representatives were found as active, and 420 were inactive. Considering their activity profile against $\mathrm{ABCB} 1, \mathrm{ABCC} 1$, and ABCG2, the 1049 compounds were classified into the following eight classes (0-7): (i) class 0 consisted of 276 molecules that had no effect on either $A B C B 1, A B C C 1$, or ABCG2 $(0,0,0)$; (ii) class 1 comprised 69 selective ABCB1 inhibitors $(1,0,0)$; (iii) class 2 contained 58 selective $A B C C 1$ inhibitors $(0,1,0)$; (iv) class 3 included 435 selective ABCG2 inhibitors $(0,0,1)$; (v) class 4 consisted of 17 dual ABCB1 and $\mathrm{ABCC} 1$ inhibitors $(1,1,0)$; (vi) class 5 comprised 122 dual $A B C B 1$ and $A B C G 2$ inhibitors $(1,0,1)$; (vii) class 6 contained 24 dual $\mathrm{ABCC} 1$ and $\mathrm{ABCG} 2$ inhibitors $(0,1,1)$; and (viii) class 7 included 48 multitarget $\mathrm{ABCB} 1, \mathrm{ABCC} 1$, and ABCG2 inhibitors $(1,1,1)$. Supplementary Table 3 provides all 1049 classified compounds with names and SMILES codes.

Basic Scaffold Search and Statistical Substructure Analysis. Two main questions should be addressed to identify the critical fingerprints for triple ABCB1, ABCC1, and ABCG2 inhibition ("multitarget fingerprints"): (i) which basic scaffolds do the 48 compounds of class 7 have and (ii) what structural features must be present for promiscuity toward ABCB1, ABCC1, and ABCG2? To address the first question, a scaffold analysis of class 7 compounds was conducted using the Structure-Activity-Report (SAReport) tool ${ }^{48}$ implemented in Molecular Operating Environment (MOE) ${ }^{49}$ From these 48 triple $A B C B 1, A B C C 1$, and $A B C G 2$ inhibitors, 35 could be categorized into six different scaffolds: (i) 4-anilinopyrimidine, (ii) pyrrolo $[3,2-d]$ pyrimidine, (iii) pyrimido $[5,4-b]$ indole, (iv) quinazoline, (v) quinoline, and (vi) thieno[2,3-b]pyridine. Figure 2 visualizes these six basic scaffolds.

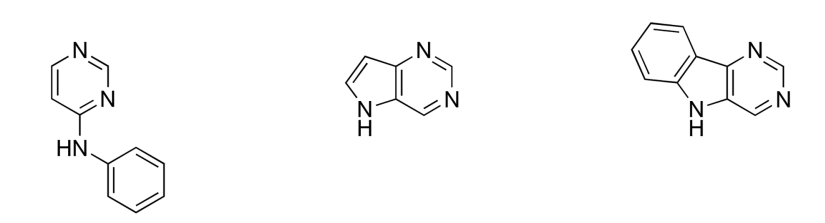

4-anilinopyrimidine

pyrrolo $[3,2-d]$ pyrimidine

pyrimido $[5,4-b]$ indole
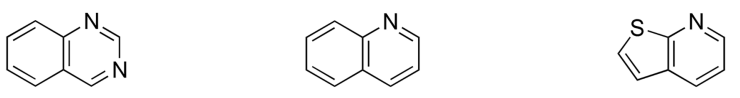

quinazoline

quinoline

thieno[2,3-b]pyridine

Figure 2. Basic scaffolds of the 48 triple $A B C B 1, A B C C 1$, and ABCG2 inhibitors using the Structure-Activity-Report (SAReport) tool $^{48}$ implemented in Molecular Operating Environment (MOE). ${ }^{49}$

Vice versa, 13 inhibitors could not be categorized, from which 11 did not have a heteroaromatic core structure. Regarding the other 2, one compound was the only representative of its structural class (thieno[2,3-b]pyrimidine). ${ }^{16}$ The other compound (apatinib) contained a pyridine, ${ }^{35}$ which was only present in three molecules and therefore did not constitute a heteroaromatic (basic) scaffold on its own according to the SAReport. ${ }^{48}$ Nevertheless, two features of these 13 non-categorizable $A B C B 1, A B C C 1$, and ABCG2 inhibitors should be highlighted: (i) the thieno$[2,3-b]$ pyrimidine and pyridine scaffolds could be subcategories of the thieno $[2,3-b]$ pyridine and quinoline scaffolds, respectively; and (ii) 9 of the 13 compounds had either dimethoxyphenyl (3 compounds) or trimethoxyphenyl (6 compounds) partial structures, which could be markers for multitarget inhibition.

To address the second question as indicated above, a list of in total 308 partial structures was compiled that are commonly present in organic molecules ${ }^{50}$ (names and SMILES codes can be found in Supplementary Table 4). The eight classes were screened against these 308 partial structures using the tool InstantJChem, ${ }^{51}$ and the absolute statistical distribution of each partial structure was collected. The relative statistical distribution was calculated, which represented the percentage of occurrence of the corresponding partial structure within the respective class $(0-7)$. As a next step, structural markers were searched for that clearly favored triple $\mathrm{ABCB} 1, \mathrm{ABCC} 1$, and ABCG2 inhibition. For this purpose, the relative statistical distribution was reorganized in five different groups: (i) group A represented the percentage of class 0 (inactive molecules); (ii) group B represented the summed percentages of classes 13 (selective inhibitors); (iii) group $\mathrm{C}$ represented the summed percentages of classes 4-6 (dual inhibitors); (iv) group D represented the percentages of class 7 (triple inhibitors); and (v) group E was calculated from the sum of the percentages of classes 4-7 [dual and triple (= multitarget) inhibitors].

Identification of Multitarget Fingerprints. From Supplementary Table 4, "clear positive hits" ("Positive Pattern") could be deduced. These were defined as the following: (i) the respective substructure must have occurred at least five times in the 1049 molecules of the dataset; (ii) group D must have 
A

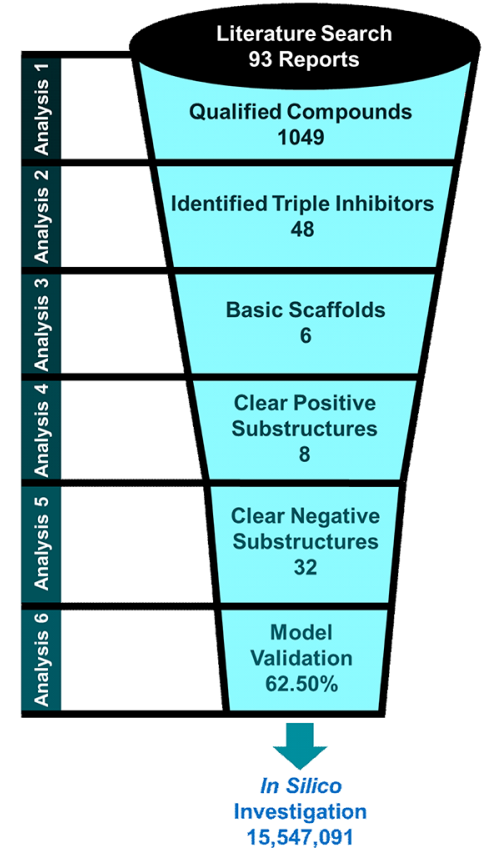

B

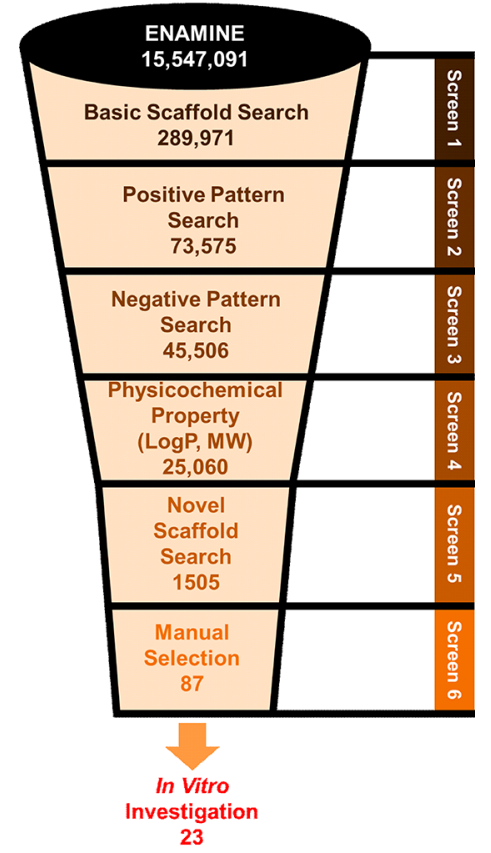

Figure 3. Schematic overview of the process of compound selection. (A) Literature search, data analysis, and development of the computer-aided pattern analysis (C@PA). (B) Screening of a virtual compound library for novel broad-spectrum ABCB1, ABCC1, and ABCG2 inhibitors.

had accounted for at least $15 \%$ of the respective hit molecules; and (iii) the percentage of group D should have been at least the same as the percentage of group B. If the second point was fulfilled but the third was not, (iv) the percentage of group E must have been at least the percentage of group B. Applying these rules, nine substructures could be found as potential markers for triple $\mathrm{ABCB} 1, \mathrm{ABCC} 1$, and $\mathrm{ABCG} 2$ inhibition: (i) isopropyl; (ii) amino; (iii) carboxylic acid ethyl ester; (iv) indole; (v) 3,4,5-trimethoxyphenyl; (vi) morpholine; (vii) thieno[2,3-b]pyridine; (viii) sulfoxide; and (ix) sulfone (Supplementary Table 4). A detailed analysis of the latter two partial substructures revealed that none of the 1049 compounds contained a sulfoxide residue but only sulfones, of which sulfoxide is a part of. Hence, we accepted only sulfone as clear positive hit for triple $\mathrm{ABCB} 1, \mathrm{ABCC} 1$, and $\mathrm{ABCG} 2$ inhibition. The thieno[2,3-b]pyridine substructure was for its part already found in the basic scaffold search.

Following the "clear positive hit" search, we defined "clear negative hits" ("Negative Pattern") that did not account for multitarget inhibition: (i) the respective substructure must have occurred at least five times in the 1049 molecules of the dataset; (ii) the respective substructure did not account for one single triple inhibitor; (iii) the percentage of group B should have been at least the same as the percentage of group C. Respecting these rules, 33 substructures could be found as potential markers for non-triple $\mathrm{ABCB} 1, \mathrm{ABCC} 1$, and ABCG2 inhibition: (i) tert-butyl; (ii) vinyl; (iii) cyclopropyl; (iv) cyclohexyl; (v) anellated cyclopropyl; (vi) anellated cycloheptyl; (vii) dimethylamino; (viii) diethylamino; (ix) nitro; (x) pyrrolidine; (xi) methylene hydroxy; (xii) ethylene hydroxy; (xiii) oxolane; (xiv) carboxylic acid; (xv) carboxylic acid methyl ester; (xvi) biphenyl; (xvii) stilbene; (xviii) 1,2,3triazole; (xix) 1,2,4-triazole; (xx) tetrazole; (xxi) pyrido[2,3-d]pyrimidine; (xxii) 1,3-dihydroisobenzofuran; (xxiii) chalcone; (xxiv) hydroquinone; (xxv) 2-methoxyphenyl; (xxvi) 3methoxyphenyl; (xxvii) 2,5-dimethoxyphenyl; (xxviii) 3,5- dimethoxyphenyl; (xxix) unsubstituted thioamide; ( $\mathrm{xxx}$ ) substituted thioamide; (xxxi) oxazole; (xxxii); urea; and (xxxiii) thiourea. As no thioamide was substituted in the 12 representatives of the 1049 compounds, only the unsubstituted thioamide partial structure has been considered as clear negative hit. Figure $3 \mathrm{~A}$ visualizes the conducted steps. In summary, the eight identified clear positive hits and 32 clear negative hits form the critical fingerprints for multitarget $\mathrm{ABCB} 1, \mathrm{ABCC} 1$, and $\mathrm{ABCG} 2$ inhibition.

Model Validation and Comparison to Classical Computational Approaches. Before screening of a large virtual compound library, the developed model for compound selection was validated by using a query search tool implemented in InstantJChem. ${ }^{51}$ The 1049 compounds served as a validation data set for "Positive Patterns" (Screen 2) and "Negative Patterns" (Screen 3), which were applied as multitarget fingerprints. Applying these two multitarget fingerprints, 30 of the 48 triple ABCB1, ABCC1, ABCG2 inhibitors could be predicted, while 18 represented false negative hits. This equals a virtual hit rate ("Sensitivity") of $62.50 \%$, while the prediction of true negatives ("Specificity") reached $90.81 \%$. To assess the quality and potential superiority of C@PA to classical computational approaches, these results were compared to (i) the 2D similarity search using MACCS fingerprints ${ }^{16}$ and (ii) pharmacophore modeling as already reported before. ${ }^{16}$ For both approaches, six query molecules of every basic scaffold have been chosen: (i) compound $\mathbf{1}$ as representative of the 4-anilinopyrimidines; ${ }^{14}$ (ii) compound 4 as representative of the pyrrolo[3,2-d] pyrimidines; $^{17}$ (iii) compound $\mathbf{5}$ as representative of the pyrimido $[5,4-b]$ indoles; $^{17}$ (iv) compound $\mathbf{6}$ as representative of the quinazolines; ${ }^{28}$ (v) compound 7 as representative of the quinolines; ${ }^{29}$ and (vi) compound 8 as representative of the thieno[2,3-b] pyridines. ${ }^{32}$ The SMILES codes and inhibitory activities of compounds 1 and $\mathbf{4 - 8}$ can be found in Supplementary Tables 1 and 2. For similarity search, MACCS fingerprints were calculated and a 
A

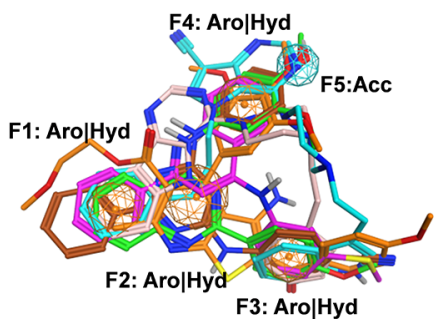

B

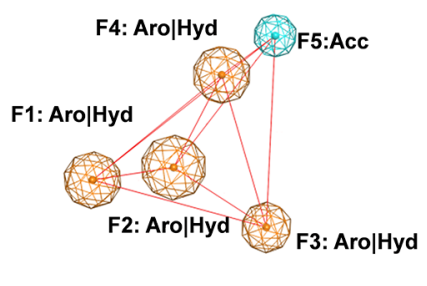

\begin{tabular}{cc}
\hline Features & Distance (Å) \\
\hline F1 - F2 & 3.26 \\
F1 - F3 & 7.24 \\
F1 - F4 & 6.68 \\
F1 - F5 & 9.37 \\
F2 - F3 & 4.48 \\
F2 - F4 & 4.21 \\
F2 - F5 & 6.73 \\
F3 - F4 & 6.43 \\
F3 - F5 & 7.78 \\
F4 - F5 & 2.69 \\
\hline
\end{tabular}

Figure 4. Flexible alignment of the six selected query molecules $\mathbf{1}$ and $\mathbf{4 - 8}$ with the five pharmacophore features F1-F5 (F1-F4: aromatic/ hydrophobic; and F5: acceptor; A), and the distances between the pharmacophore features are shown in $\AA$ as red lines (B), and the distance values can be found in the table to the right.

Table 1. Absolute and Relative Hit Values As Obtained from C@PA Compared to Two Classical Computational Approaches, Similarity Search and Pharmacophore Modeling ${ }^{a}$

\begin{tabular}{|c|c|c|c|c|c|c|}
\hline \multirow[b]{2}{*}{ Class (Compounds) } & \multicolumn{2}{|c|}{ C@PA } & \multicolumn{2}{|c|}{$\begin{array}{l}\text { Similarity } \\
\text { Search }\end{array}$} & \multicolumn{2}{|c|}{$\begin{array}{l}\text { Pharmacophore } \\
\text { Modeling }\end{array}$} \\
\hline & $\begin{array}{c}\text { Hit } \\
\text { Compounds }\end{array}$ & Percentage & $\begin{array}{c}\text { Hit } \\
\text { Compounds }\end{array}$ & Percentage & \begin{tabular}{|c|} 
Hit \\
Compounds
\end{tabular} & Percentage \\
\hline Class0 (276) & 26 & 9.42 & 16 & 5.80 & 121 & 43.84 \\
\hline Class1 (69) & 13 & 18.84 & 0 & 0.00 & 51 & 73.91 \\
\hline Class2 (58) & 8 & 13.79 & 24 & 41.38 & 24 & 41.38 \\
\hline Class3 (435) & 13 & 2.99 & 42 & 9.66 & 237 & 54.48 \\
\hline Class4 (17) & 5 & 29.41 & 4 & 23.53 & 14 & 82.35 \\
\hline Class5 (122) & 25 & 20.49 & 30 & 24.59 & 104 & 85.25 \\
\hline Class6 (24) & 2 & 8.33 & 11 & 45.83 & 5 & 20.83 \\
\hline Class7 (48) & 30 & 62.50 & 21 & 43.75 & 29 & 60.42 \\
\hline Sensitivity & \multicolumn{2}{|c|}{62.50} & \multicolumn{2}{|c|}{43.75} & \multicolumn{2}{|c|}{60.42} \\
\hline Specificity & \multicolumn{2}{|c|}{90.81} & \multicolumn{2}{|c|}{87.31} & \multicolumn{2}{|c|}{44.46} \\
\hline
\end{tabular}

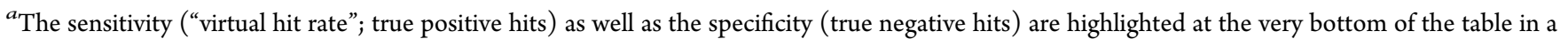
rose mark.

Tanimoto coefficient (Tc) with a cutoff value of 0.8 has been applied. As a result, the sensitivity of this approach yielded in $43.75 \%$, while the specificity reached $87.31 \%$. Regarding the pharmacophore modeling, a flexible alignment of the stated compounds has been performed applying MOE (Figure 4A). ${ }^{49}$ Using the consensus methodology implemented in the Pharmacophore Query Editor, five pharmacophore features [(i-iv) F1-F4: aromatic/hydrophobic; and (v) F5: acceptor] were identified that were present in at least four of the six query molecules $\mathbf{1}$ and 4-8 (tolerance distance: $1.2 \AA$; threshold value: $>50 \%$; Figure $4 \mathrm{~B}$ ). The sensitivity of this approach reached $60.42 \%$, while the specificity had a value of $44.46 \%$. Table 1 gives the prediction values for each class and computational approach. As it turned out, C@PA combined the high sensitivity of the pharmacophore modeling with the high specificity of the similarity search and, moreover, slightly exceeded these values. As its superiority was proven in the process of model validation, we felt confident to continue with large-scale virtual screening.

Virtual Screening, Selection Criteria, and Manual Candidate Selection. For the discovery of novel triple $\mathrm{ABCB} 1, \mathrm{ABCC} 1$, and $\mathrm{ABCG} 2$ inhibitors, the ENAMINE Diverse REAL drug-like compound library comprising $15,547,091$ molecules was taken for virtual screening. ${ }^{52}$ Three initial selection criteria were formulated: (i) the compound must have contained at least one of the six identified basic scaffolds (Screen 1: "Scaffold Search"; Figure 2); (ii) the compound must have contained at least one of the defined clear positive hits (Screen 2: "Positive Pattern"); and (iii) the compounds must not have been equipped with any of the clear negative hits (Screen 3: "Negative Pattern"). In total, 289,971 compounds had at least one basic scaffold. Amongst these, 73,575 candidates included at least one clear positive hit substructure, while 45,506 of them did not have any clear negative hit substructure. Furthermore, compounds were excluded if they did not have a partition coefficient $(\log P)$ as well as molecular weight (MW) that stretched inside the span of $\log \mathrm{P}$ and MW of class 7 compounds (Screen 4; LogP span: 2.4-6.9; MW span: 295-915). This downsized the compound library to 25,060 potential multitarget $A B C B 1$, $\mathrm{ABCC} 1$, and $\mathrm{ABCG} 2$ inhibitors.

In order to obtain novel agents that had scaffolds not associated with simultaneous inhibition of $\mathrm{ABCB} 1, \mathrm{ABCC} 1$, and ABCG2 before, substructures of Supplementary Table 4 were emphasized that have not been part of any of the 1049 molecules, which was the case for 146 substructures. The focus of this work was to discover new heteroaromatic scaffolds as multitarget $\mathrm{ABCB} 1, \mathrm{ABCC} 1$, and $\mathrm{ABCG} 2$ inhibitors. Hence, out of the 146 novel substructures, 29 heteroaromatic scaffolds were chosen: (i) benzopyrazole; (ii) pyrrolo[3,2-b]pyridine; (iii) pyrrolo[3,2-c]pyridine; (iv) pyrrolo[2,3-c]pyridine; (v) carbazole; (vi) phthalazine; (vii) pyrido $[3,2-d]$ pyrimidine; (viii) pyrido $[4,3-d]$ pyrimidine; (ix) pyrimido $[4,5-d]$ pyrimidine; (x) pteridine; (xi) 1,2,3-triazine; (xii) dibenzofuran; (xiii) dibenzothiophene; (xiv)1,2,3-oxadiazole; (xv) 1,2,4oxadiazole; (xvi) 1,2,5-oxadiazole; (xvii) isothiazole; (xviii) 1,2,3-thiadiazole; (xix) 1,2,4-thiadiazole; (xx) 1,2,5-thiadiazole; (xxi) 1,3,4-thiadiazole; (xxii) furo[3,2-b]pyridine; (xxiii) furo$[3,2-c]$ pyridine; (xxiv) furo[2,3-c]pyridine; (xxv) furo[2,3-d]pyrimidine; (xxvi) furo[3,2-d]pyrimidine; (xxvii) thieno$[3,2-b]$ pyridine; (xviii) thieno[3,2-c]pyridine; and (xxix) thieno[2,3-c]pyridine. Screening of these 25,060 compounds resulted in 1505 novel heteroaromatic putative $\mathrm{ABCB} 1$, 
A

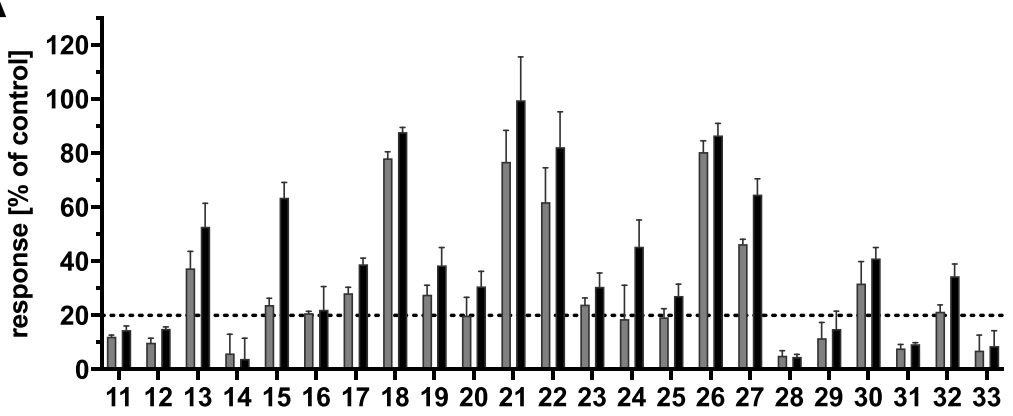

B
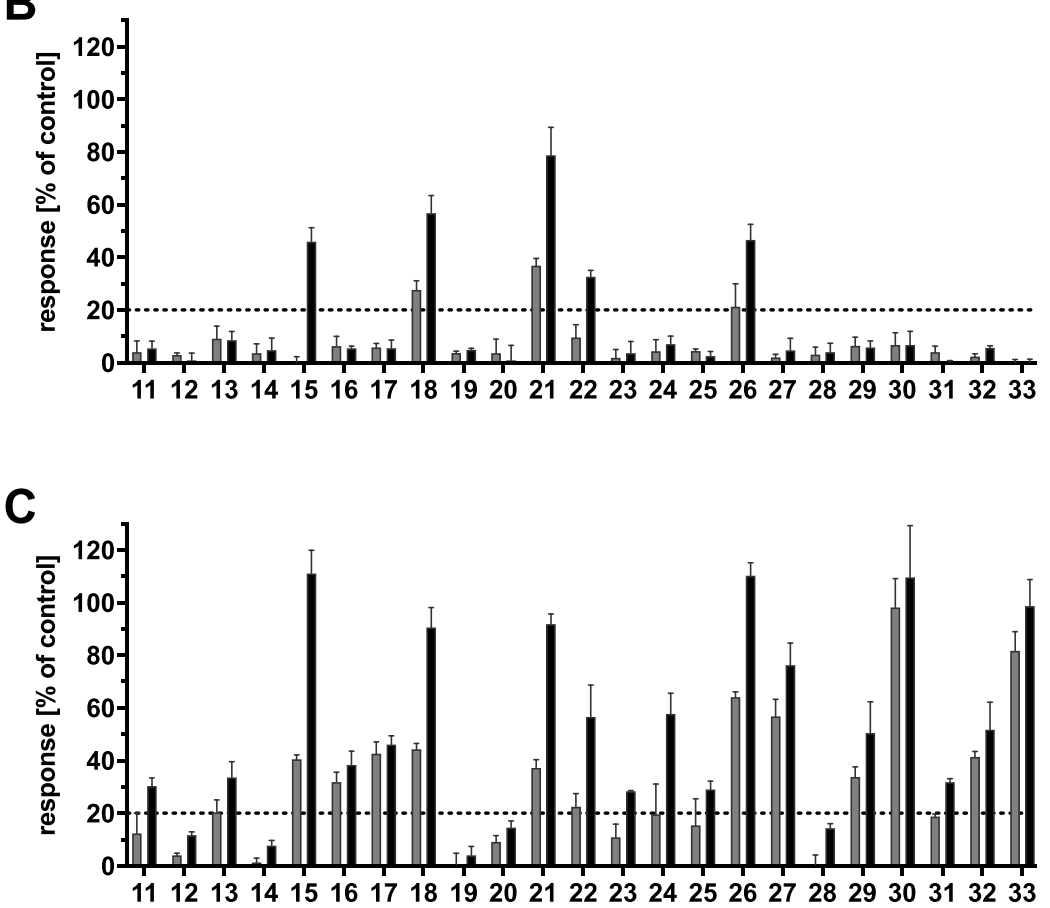

Figure 5. Inhibitory effect of compounds 11-33 at $5 \mu \mathrm{M}$ (grey) and $10 \mu \mathrm{M}$ (black) against $\mathrm{ABCB} 1$ (A), ABCC1 (B), and ABCG2 (C) using either ABCB1-overexpressing A2780/ADR cells (A), ABCC1-overexpressing H69AR cells (B), or ABCG2-overexpressing MDCK II BCRP cells (C) in either calcein AM (A and B) or pheophorbide A (C) assays. Data were normalized by defining the effect of $10 \mu \mathrm{M}$ cyclosporine A (A and B) and compound $34(\mathrm{C})$ as a positive control $(100 \%)$ and buffer medium as a negative control $(0 \%)$. Shown is the mean \pm standard error of the mean (SEM) of at least three independent experiments.

ABCC1, and ABCG2 inhibitors (Screen 5: "Novel Scaffold Search"; Supplementary Table 5).

Regarding the basics scaffolds, these 1505 molecules comprised (i) 35 4-anilinopyrimidines, (ii) 0 pyrrolo[3,2-d]pyrimidines, (iii) 0 pyrimido[5,4-b]indoles, (iv) 232 quinazolines, (v) 1007 quinolines, and (vi) 241 thieno[2,3-b]pyridines. With respect to the positive patterns, (i) 531 compounds had an isopropyl residue, (ii) 334 contained an amino group, (iii) 56 were carboxylic acid ethyl esters, (iv) 86 were indoles, (v) 2 possessed a 3,4,5-trimethoxyphenyl partial structure, (vi) 38 possessed a morpholine, (vii) 241 were thieno[2,3-b] pyridines, and (viii) 339 comprised a sulfone substructure. From this compilation of candidates, compounds 11-33 were assembled through a manual selection. In this manual selection, substituents were in focus that have shown in previous studies to strongly engage the $\mathrm{ABC}$ transporter inhibitor with their respective target, ${ }^{27-29,53,54}$ e.g., fluorine $(\mathbf{1 7 - 1 8}, \mathbf{2 1}, \mathbf{2 9 - 3 0}$, and 32), chlorine $(16-17,23,31$, and 33$)$, cyano $(18,26)$, or methoxy $(15,21,24,26,28$, and 31$)$, if possible at the main scaffolds and in combination with one another $(17-18,21,26$, 31). Furthermore, the molecules should be two-centered (11$13,18,20,22-23,26,28-30$, and 33), three-centered (14$17,19,21,24-25$, and 31-32), or four-centered (27) with linkers of different size connecting each of the (hetero)aromatic centers. Finally, piperazine (11 and 22) and piperazine-like linkers [homo-piperazine (13 and 18) and piperidine (26)] were emphasized since piperazine is often present as a linker in multitarget $A B C$ transporter inhibitors. ${ }^{16,17,53-55}$ In essence, these experience-based decisions as well as availability and price of the compounds led to the selection of 87 candidates, from which 43 were ordered from ENAMINE. Amongst these 43 compounds, 23 were available for delivery within the purity requirement of $95 \%$ (compounds 11-33; Supplementary Table 6) and were subject to subsequent biological evaluation. Figure $3 \mathrm{~B}$ summarizes the virtual screening processes of C@PA.

Biological Investigation. Assessment of Potential Triple $A B C B 1, A B C C 1$, and $A B C G 2$ Inhibitors. Compounds 11-33 
were screened at 5 and $10 \mu \mathrm{M}$ in calcein $\mathrm{AM}$ (ABCB1 and $\mathrm{ABCC} 1$ ) and pheophorbide A (ABCG2) fluorescence accumulation assays. This was performed using either ABCB1-overexpressing A2780/ADR, ABCC1-overexpressing H69AR, or ABCG2-overexpressing MDCK II BCRP cells as reported earlier. ${ }^{14-16,56}$ In short, calcein AM and pheophorbide $A$ are $A B C$ transporter substrates that diffuse into the cells and get effluxed by the respective $A B C$ transporter. In the case of $\mathrm{ABC}$ transporter inhibition, the corresponding substrate accumulates inside the cell. Unspecific esterases cleave calcein AM to the fluorescent calcein, which becomes trapped inside the cells because of its free acid groups. In this state, it is easily detectable using a microplate reader. On the other hand, pheophorbide $\mathrm{A}$ is already fluorescent and has been evaluated via flow cytometry. In both assays, the amount of measured intracellular fluorescence correlated with the degree of inhibition of the respective transporter. Cyclosporine A (10 $\mu \mathrm{M})$ and $\mathrm{Ko} 143[(3 S, 6 S, 12 \mathrm{a} S)-1,2,3,4,6,7,12,12 \mathrm{a}$-octahydro-9methoxy-6-(2-methylpropyl)-1,4-dioxopyrazino $\left[1^{\prime}, 2^{\prime}: 1,6\right]$ pyrido[3,4-b] indole-3-propanoic acid 1,1-dimethylethyl ester; compound $34 ; 10 \mu \mathrm{M}$ ] have been chosen as positive controls for $\mathrm{ABCB} 1$ and $\mathrm{ABCC} 1$ as well as $\mathrm{ABCG} 2$, respectively, defining $100 \%$ inhibition.

As can be seen from Figure 5A-C, 17, 5, and 18 of the 23 compounds showed an inhibitory activity against $\mathrm{ABCB} 1$ (A), $A B C C 1$ (B), and ABCG2 (C), respectively, of over $20 \%$ [+ standard error or the mean (SEM) $]$. Hence, complete concentration-effect curves have been generated to obtain $\mathrm{IC}_{50}$ values for these compounds, which are summarized in Table 2. Compounds 15, 18, 21, 22, and 26 could be identified as triple $\mathrm{ABCB} 1, \mathrm{ABCC} 1$, and $\mathrm{ABCG} 2$ inhibitors and are depicted in Figure 6.

The most potent representative, compound 21 , had $\mathrm{IC}_{50}$ values of 2.64, 5.63, and $6.27 \mu \mathrm{M}$ against $\mathrm{ABCB} 1, \mathrm{ABCC} 1$, and ABCG2, respectively. This makes compound 21 belonging to the around 50 most potent multitarget $\mathrm{ABCB} 1, \mathrm{ABCC} 1$, and ABCG2 inhibitors, ${ }^{14-17,21,23,25-42}$ which is also true for compounds 18 and 26. Figure $7 \mathrm{~A}-\mathrm{C}$ shows the concentration-effect curves of compound 21, while Supplementary Figures $1 \mathrm{~A}-\mathrm{C}, 2 \mathrm{~A}-\mathrm{C}, 3 \mathrm{~A}-\mathrm{C}$, and $4 \mathrm{~A}-\mathrm{C}$ show the concentration-effect curves of compounds 15, 18, 22, and 26, respectively, obtained in the calcein AM and pheophorbide A assays. Considering the 23 evaluated compounds, the finding of five multitarget $\mathrm{ABCB} 1, \mathrm{ABCC} 1$, and $\mathrm{ABCG} 2$ inhibitors represents a biological hit rate of $21.7 \%$.

In addition, two compounds revealed a remarkable inhibitory power against ABCG2: the quinoline/1,2,4oxadiazole/indole derivative $26\left(\mathrm{IC}_{50}=0.540 \pm 0.150 \mu \mathrm{M}\right.$; Figure 7) and the pyrimidine/1,2,4-oxadiazole/indole derivative $27\left(\mathrm{IC}_{50}=0.220 \pm 0.020 \mu \mathrm{M}\right.$; Figure 8$)$. This is a special finding given the fact that screenings usually do not provide compounds with very high activities. Especially, the results for compound 27 must be put into perspective as it possessed an equal inhibitory power against ABCG2 as the "golden standard", compound 34. Hence, it represents a promising lead molecule for ongoing research.

Confirmation of Inhibitory Power of Compounds 15, 18, $21,22,26$, and 27. In order to confirm the found results with respect to multitarget $A B C B 1, A B C C 1$, and $A B C G 2$ inhibition of compounds 15, 18, 21, 22, and 26 as well as ABCG2 inhibition of compound 27, Hoechst 33342 (ABCB1 and ABCG2), ${ }^{15,57}$ and daunorubicin (ABCC1) ${ }^{17}$ fluorescence accumulation assays have been performed as described
Table 2. $\mathrm{IC}_{50}$ Values of Active Compounds That Had an Inhibition Level of At Least 20\% [+ Standard Error of the Mean (SEM)] against ABCB1, ABCC1, and/or ABCG2 in the Initial Screening (Figure $5 \mathrm{~A}-\mathrm{C})^{\#}$

\begin{tabular}{|c|c|c|c|}
\hline Compound & $\begin{array}{c}\mathrm{IC}_{50} \pm \mathrm{SEM}[\mathrm{SM}] \\
\text { ABCB1 } \\
\text { Calcein AM }\end{array}$ & $\begin{array}{c}\mathrm{IC}_{50} \pm \mathrm{SEM}[\mu \mathrm{M}] \\
\text { ABCC1 } \\
\text { Calcein AM }\end{array}$ & $\begin{array}{c}\mathrm{IC}_{50} \pm \mathrm{SEM}[\mu \mathrm{M}] \\
\text { ABCG2 } \\
\text { Pheophorbide A }\end{array}$ \\
\hline 11 & n.d. $^{a}$ & n.d. ${ }^{a}$ & $20.3 \pm 0.2$ \\
\hline 12 & n.d. ${ }^{a}$ & n.d. ${ }^{a}$ & n.d. ${ }^{a}$ \\
\hline 13 & $10.9 \pm 1.2$ & n.d. ${ }^{a}$ & $18.6 \pm 5.2$ \\
\hline 14 & n.d. ${ }^{a}$ & n.d. ${ }^{a}$ & n.d. ${ }^{a}$ \\
\hline 15 & $8.59 \pm 0.57$ & $11.0 \pm 0.4$ & $1.31 \pm 0.17$ \\
\hline 16 & $17.0 \pm 2.0$ & n.d. $^{a}$ & $10.3 \pm 0.8$ \\
\hline 17 & $14.5 \pm 1.5$ & n.d. ${ }^{a}$ & $7.33 \pm 0.75$ \\
\hline 18 & $2.53 \pm 0.17$ & $9.11 \pm 0.78$ & $1.98 \pm 0.21$ \\
\hline 19 & $17.7 \pm 3.6$ & n.d. $^{a}$ & n.d. $^{a}$ \\
\hline 20 & $29.1 \pm 3.2$ & n.d. ${ }^{a}$ & n.d. ${ }^{a}$ \\
\hline 21 & $2.64 \pm 0.34$ & $5.63 \pm 0.69$ & $6.27 \pm 0.74$ \\
\hline 22 & $3.64 \pm 0.31$ & $14.2 \pm 0.2$ & $9.07 \pm 1.17$ \\
\hline 23 & $25.0 \pm 5.6$ & n.d. $^{a}$ & $18.1 \pm 1.3$ \\
\hline 24 & $16.2 \pm 2.0$ & n.d. ${ }^{a}$ & $8.11 \pm 0.75$ \\
\hline 25 & $32.7 \pm 9.1$ & n.d. ${ }^{a}$ & $17.4 \pm 3.0$ \\
\hline 26 & $2.00 \pm 0.14$ & $9.66 \pm 0.65$ & $0.540 \pm 0.150$ \\
\hline 27 & $5.75 \pm 0.76$ & n.d. $^{a}$ & $0.220 \pm 0.020$ \\
\hline 28 & n.d. $^{a}$ & n.d. ${ }^{a}$ & n.d. ${ }^{a}$ \\
\hline 29 & n.d. ${ }^{a}$ & n.d. ${ }^{a}$ & $16.2 \pm 6.2$ \\
\hline 30 & $13.7 \pm 1.9$ & n.d. ${ }^{a}$ & $1.08 \pm 0.30$ \\
\hline 31 & n.d. ${ }^{a}$ & n.d. ${ }^{a}$ & $23.6 \pm 2.6$ \\
\hline 32 & $19.6 \pm 3.3$ & n.d. ${ }^{a}$ & $7.11 \pm 0.68$ \\
\hline 33 & n.d. ${ }^{a}$ & n.d. ${ }^{a}$ & $1.46 \pm 0.12$ \\
\hline
\end{tabular}

${ }^{\#}$ ABCB1-overexpressing A2780/ADR, ABCC1-overexpressing H69AR, or ABCG2-overexpressing MDCK II BCRP cells in either calcein $\mathrm{AM}$ (ABCB1 and $\mathrm{ABCC} 1)$ or pheophorbide A (ABCG2) assays were used. ${ }^{14-16,56}$ The positive control $(100 \%)$ was defined by the effect value of $10 \mu \mathrm{M}$ cyclosporine $\mathrm{A}$ (ABCB1 and $\mathrm{ABCC} 1)$ or compound 34 (ABCG2), while buffer medium served as a negative control $(0 \%)$. Shown is the mean \pm SEM of at least three independent experiments. Rose mark: discovered triple $\mathrm{ABCB} 1, \mathrm{ABCC} 1$, and ABCG2 inhibitors. ${ }^{a}$ No $\mathrm{IC}_{50}$ determined due to lack of inhibitory activity in the initial screening (Figure $5 \mathrm{~A}-\mathrm{C}$ ).

previously ${ }^{15,17,57}$ with minor modifications, using either ABCB1-overexpressing A2780/ADR, ABCC1-overexpressing H69AR, or ABCG2-overexpressing MDCK II BCRP cells. In short, Hoechst 33342 and daunorubicin are substrates of $A B C$ transporters that passively diffuse into the cells and become extruded by the respective $\mathrm{ABC}$ transporter. $\mathrm{ABC}$ transporter inhibition leads to an intracellular accumulation of these fluorescence dyes. Hoechst 33342 intercalates with the DNA in the nucleus and accumulates in intracellular membrane bilayers, both leading to a fluorescent complex that could be detected using a microplate reader. On the other hand, daunorubicin is already fluorescent and has been evaluated via flow cytometry. In both assays, the measured fluorescence values correlated with the degree of inhibition of the respective transporter. Ten micromolar cyclosporine A and compound 34 have been used as references to define $100 \%$ inhibition of $\mathrm{ABCB} 1$ and $\mathrm{ABCC} 1$ as well as $\mathrm{ABCG} 2$, respectively. The data for the multitarget $\mathrm{ABCB} 1, \mathrm{ABCC} 1$, and $\mathrm{ABCG} 2$ inhibitors 15, 18, 21, 22, and 26 are summarized in Table 3.

Compounds 15, 18, 21, 22, and 26 could be confirmed as triple $A B C B 1, A B C C 1$, and $A B C G 2$ inhibitors. Generally, the $\mathrm{IC}_{50}$ values correlated with the values of the calcein $\mathrm{AM}$ (ABCB1 and $A B C C 1)$ and pheophorbide A (ABCG2) assays (Table 2). Only the $\mathrm{IC}_{50}$ value of compound $\mathbf{2 6}$ determined in the daunorubicin assay (ABCC1) fell out of the correlation, which was with $0.764 \mu \mathrm{M}$ over 12 times lower than could have 


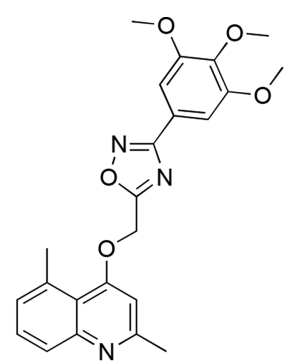

quinoline/1,2,4-oxadiazole 15<smiles>CC(C)c1ccc2ncc(C#N)c(N3CCCN(c4nnc(C(F)(F)F)s4)CC3)c2c1</smiles>

quinoline/1,3,4-thiadiazole 18

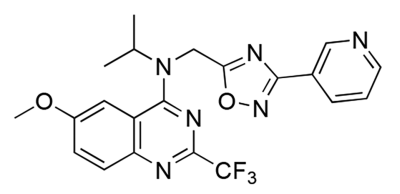

quinazoline/1,2,4-oxadiazole 21

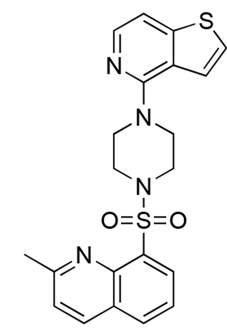

quinoline/thieno[3,2-c]pyridine 22

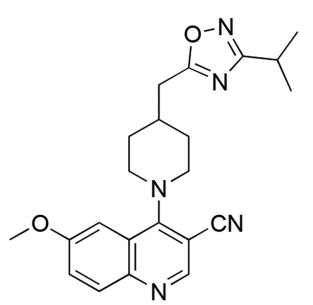

quinoline/1,2,4-oxadiazole 26

Figure 6. $2 \mathrm{D}$ representation of multitarget $\mathrm{ABCB} 1, \mathrm{ABCC} 1$, and $\mathrm{ABCG} 2$ inhibitors discovered in this work: the quinoline and 1,2,4-oxadiazole derivative 15, the quinoline and 1,3,4-thiadiazole derivative 18, the quinazoline and 1,2,4-oxadiazole derivative 21, the quinoline and thieno[3,2-c] pyridine derivative 22 , as well as the quinoline and 1,2,4-oxadiazole derivative 26 .

been expected from the calcein AM data. However, these discrepancies frequently occur as $\mathrm{IC}_{50}$ values generally depend on the used fluorescence dye, in particular its polarity, lipophilicity, (velocity of) membrane distribution, and affinity to the respective transporter. ${ }^{15,24,58}$ Again, compound 21 was the most potent representative of the five triple inhibitors with $\mathrm{IC}_{50}$ values of $4.53,2.33$, and $4.45 \mu \mathrm{M}$ against $\mathrm{ABCB} 1$, $\mathrm{ABCC} 1$, and $\mathrm{ABCG} 2$, respectively. Considering these values, compound 21 belongs even to the 23 most potent multitarget in hibitors of A B C B 1, A B C C 1, a n d ABCG2. ${ }^{14,15,21,23,25,26,28,32,34,37-39}$ The corresponding concentration-effect curves derived in the Hoechst 33342 and daunorubicin assays are shown in Figure $7 \mathrm{D}-\mathrm{F}$, while the dose-response curves of compounds 15, 18, 22, and 26 determined in the very same assays are depicted in Supplementary Figures 1D-F, 2D-F, 3D-F, and 4D-F. Additionally, the high inhibitory power of compound 27 could be confirmed as it had an $\mathrm{IC}_{50}$ value of $0.260 \mu \mathrm{M}$ in the Hoechst 33342 assay. In all, the results of the calcein AM and pheophorbide A assays could be confirmed, which finally gave proof that critical fingerprints have been identified to predict multitarget $\mathrm{ABC}$ transporter inhibitors by C@PA.

\section{DISCUSSION AND CONCLUSIONS}

$\mathrm{C} @ \mathrm{PA}$ was a major success, as a prediction of multitarget $\mathrm{ABC}$ transporter inhibitors has never been postulated and biologically proven before. More strikingly, compounds 15, 18, 21, 22, and 26 belong to the structural classes of 1,2,4oxadiazoles, 1,3,4-thiadiazoles, and thieno[3,2-c]pyridines. While 1,2,5-oxadiazoles ${ }^{59-62}$ have frequently been reported as (selective ${ }^{59-62}$ or $\mathrm{dual}^{62}$ ) $\mathrm{ABCB} 1^{59,60,62}$ and $\mathrm{ABCC} 1$ inhibitors, $^{61,62}$ 1,2,4-oxadiazoles ${ }^{63-65}$ have only once been reported as selective $\mathrm{ABCG} 2$ inhibitors $^{65}$ or reversers of ABCB1-, ABCC1-, or ABCG2-mediated MDR. ${ }^{63,64} 1,3,4-$
Thiadiazoles have also only once been reported in association with selective, dual, or triple $\mathrm{ABCB} 1, \mathrm{ABCC} 1$, and $\mathrm{ABCG} 2$ inhibition. ${ }^{66}$ However, these compounds had estimated $\mathrm{IC}_{50}$ values of far beyond $25 \mu \mathrm{M}$. ${ }^{66}$ Thieno[3,2-c] pyridines, on the other hand, have never been associated with either ABCB1, ABCC1, or ABCG2.

A biological hit rate of $21.7 \%$ is common for single-target computational approaches as reported in the literature that subsequently validated their postulations with biological studies. ${ }^{67-71}$ However, this number is very impressive for multitarget screening studies, in particular considering the huge challenges involved in the development of C@PA. We identified four major aspects that impacted the model development.

The first aspect is related to the selection of molecules as basis for the development of C@PA. The amount of data that could be used was highly limited. We found only 93 reports containing 1049 compounds that qualified for data processing. Many compounds were not characterized in full by complete concentration-effect curves and had to be estimated for a proper compound categorization and classification. The data processing procedures in these 93 reports that led to the published $\mathrm{IC}_{50}$ values were not standardized (e.g., three- vs four-parameter logistic equation). Some $\mathrm{IC}_{50}$ values provided a limited number of significant digits or were not accompanied by standard deviations or standard errors. Furthermore, certain $\mathrm{IC}_{50}$ values resulted from so-called "partial inhibitors" ( $\mathrm{IC}_{50 \text { absolute }}$ vs $\left.\mathrm{IC}_{50 \text { relative }}\right)$. Additionally, the applied assay systems were not standardized and varied within the 93 reports. While a majority of testing systems was accumulation (uptake) assays, some findings were based on efflux experiments. Furthermore, the transporter host system varied in the reported biological studies. While the majority of authors used living cells, some used inside-out membrane vesicles, both for 
A

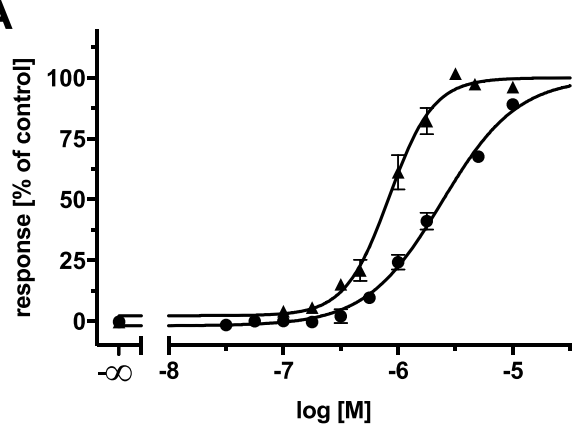

C

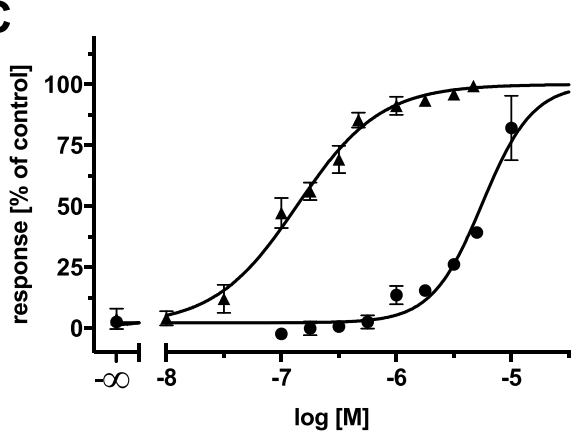

E

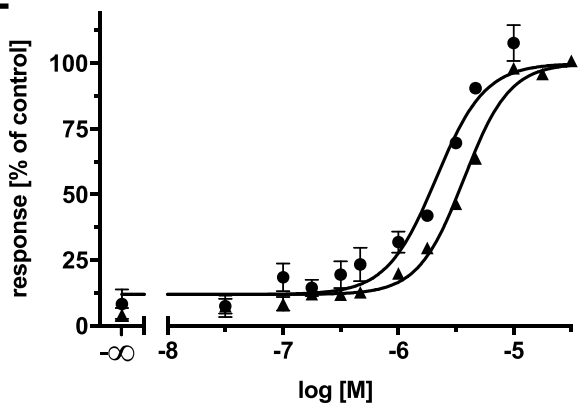

B

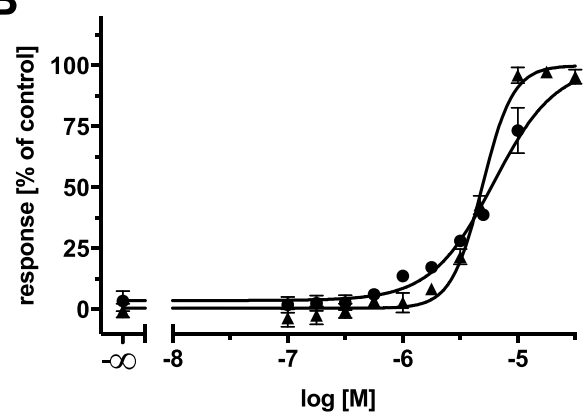

D

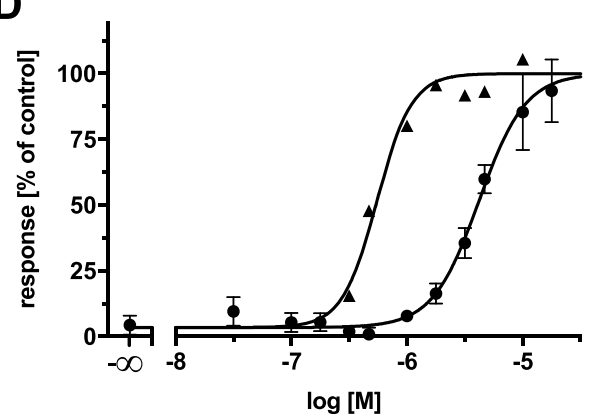

$\mathbf{F}$

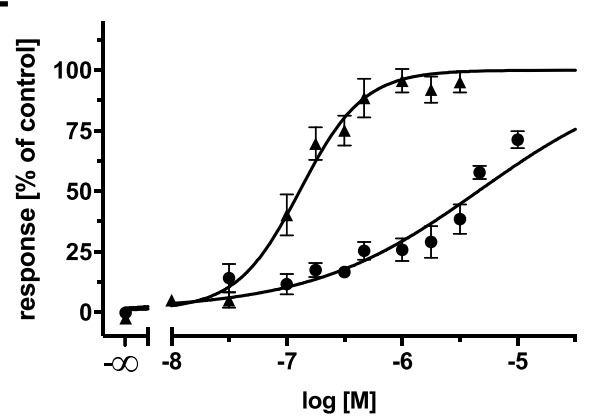

Figure 7. Concentration-effect curves of compound $21(0)$ against $\mathrm{ABCB} 1$ (A and D), ABCC1 (B and E), and ABCG2 (C and F) as determined in calcein AM (A and B), pheophorbide A (C), Hoechst 33342 (D and F), and daunorubicin (E) assays using ABCB1-overexpressing A2780/ADR cells (A and D), ABCC1-overexpressing H69AR cells (B and E), or ABCG2-overexpressing MDCK II BCRP cells (C and F). Data were normalized by defining the effect of $10 \mu \mathrm{M}$ cyclosporine $\mathrm{A}(\boldsymbol{\Lambda} ; \mathrm{A}, \mathrm{B}, \mathrm{D}$, and $\mathrm{E})$ and compound $34(\boldsymbol{\Lambda} ; \mathrm{C}$ and $\mathrm{F})$ as a positive control $(100 \%)$ and buffer medium as a negative control $(0 \%)$. Shown is the mean \pm SEM of at least three independent experiments.<smiles>Cn1cc(-c2nc(-c3cc(Nc4ccccc4)ncn3)no2)c2ccccc21</smiles>

pyrimidine/1,2,4-oxadiazole/indole 27

Figure 8. Molecular formula of the very potent ABCG2 inhibitor 27 $\left(\mathrm{IC}_{50 \text { Pheophorbide } \mathrm{A}}=0.220 \mu \mathrm{M} ; \mathrm{IC}_{50 \text { Hoechst } 33342}=0.260 \mu \mathrm{M}\right)$ as discovered in the herein presented virtual screening approach.

its part influencing compound distribution and binding, but also transporter abundance and functionality (e.g., pump rate). ${ }^{24}$ The living cells for their part were either transfected or selected cells, which impacted the expression and abundance of (functional) transport protein and eventually the inhibitory activity against the respective transporter. More
Table 3. Confirmation of $\mathrm{IC}_{50}$ Values of Compounds 15, 18, 21,22 , and $26^{a}$

\begin{tabular}{c|c|c|c} 
Compound & $\begin{array}{c}\mathbf{I C}_{50} \pm \text { SEM }[\mu \mathrm{M}] \\
\text { ABCB1 } \\
\text { Hoechst 33342 }\end{array}$ & $\begin{array}{c}\text { IC }_{50} \pm \text { SEM }[\mu \mathrm{M}] \\
\text { ABCC1 } \\
\text { Daunorubicin }\end{array}$ & $\begin{array}{c}\mathbf{I C}_{50} \pm \text { SEM }[\mu \mathrm{M}] \\
\text { ABCG2 } \\
\text { Hoechst 33342 }\end{array}$ \\
\hline $\mathbf{1 5}$ & $13.1 \pm 1.5$ & $16.7 \pm 4.8$ & $0.600 \pm 0.050$ \\
\hline $\mathbf{1 8}$ & $5.88 \pm 0.55$ & $2.26 \pm 0.16$ & $3.91 \pm 0.20$ \\
\hline $\mathbf{2 1}$ & $4.53 \pm 0.52$ & $2.33 \pm 0.07$ & $4.45 \pm 0.28$ \\
\hline $\mathbf{2 2}$ & $6.18 \pm 0.73$ & $4.38 \pm 0.22$ & $14.2 \pm 2.1$ \\
\hline $\mathbf{2 6}$ & $5.87 \pm 1.28$ & $0.764 \pm 0.115$ & $0.810 \pm 0.140$ \\
\hline
\end{tabular}

${ }^{a}$ Hoechst 33342 and daunorubicin assays were conducted using either ABCB1-overexpressing A2780/ADR, ABCC1-overexpressing H69AR, or ABCG2-overexpressing MDCK II BCRP cells as reported earlier. ${ }^{15,17,57}$ Cyclosporine $\mathrm{A}(10 \mu \mathrm{M}$; $\mathrm{ABCB} 1$ and $\mathrm{ABCC} 1)$ and compound $34(10 \mu \mathrm{M}$; ABCG2) were used as a reference for $100 \%$ inhibition, and buffer medium represented $0 \%$. Shown is the mean \pm SEM of at least three independent experiments.

importantly, a great variety of fluorescence dyes has been used to assess the corresponding compounds. It is well known that 
inhibitory activity can be strongly dependent on the manner of the fluorescence dye [e.g., its polarity, lipophilicity, velocity of diffusion and distribution, as well as affinity toward the transporter(s)]. ${ }^{15,24,58}$ Moreover, fluorescence measurements themselves pose a risk of artifacts, which can be explained by secondary effects like quenching (with each other or with the evaluated compounds). This can be circumvented by the use of other types of measurements, like radioactivity counts in radionuclide studies. However, this kind of testing system has only been used by a minority of authors. Finally, it must be taken into consideration that the 93 reports came from various laboratories with different non-standardized assay procedures, resulting in the very same assay being executed in various manners. Taken these data-related aspects together, the errors of each individual aspect collectively potentiated, giving a final uncertainty for C@PA's prediction capabilities.

The second major aspect stems from the initial categorization of compounds into "active" and "inactive". The "activity threshold" has been set to $10 \mu \mathrm{M}$. A threshold in general adversely affects compounds close to the chosen value, which inevitably leads to misclassifications. However, only 19 (ABCB1), 24 (ABCC1), and 42 (ABCG2) so-called "borderline-compounds", where the $\mathrm{IC}_{50} \pm \mathrm{SD} / \mathrm{SEM}$ values either overlapped with the threshold of $10 \mu \mathrm{M}$, or were defined as "around $10 \mu \mathrm{M}$ " $(\sim 10)$ or exactly $10 \mu \mathrm{M}(10.000)$, have been identified from Supplementary Table 1. Hence, the problem of miscategorization of the compounds is rather negligible. Although the value of $10 \mu \mathrm{M}$ seems to be quite high, one must take into account that broad-spectrum $\mathrm{ABCB} 1, \mathrm{ABCC} 1$, and $\mathrm{ABCG} 2$ inhibitors generally exert their effect almost always in the single- to double-digit micromolar concentration range. As stated out in the Introduction, only about 50 triple $A B C B 1, A B C C 1$, and $A B C G 2$ inhibitors exerted their effect below $10 \mu \mathrm{M},{ }^{14-17,21,23,25-42}$ and only 22 of them had activities below $5 \mu \mathrm{M}^{14,15,21,23,25,26,28,32,34,37-39}$ Setting the threshold to higher activities (lower $\mathrm{IC}_{50}$ values) would have led to a radical downsizing of the data set. This would not have left enough space for action and interpretation. Even setting the threshold at $10 \mu \mathrm{M}$ allowed only for 48 triple $\mathrm{ABCB} 1$, $A B C C 1$, and $A B C G 2$ inhibitors to be considered as a basis of scaffold analysis and the following computational measures. A higher threshold would have led to a larger number of triple $A B C B 1, A B C C 1$, and $A B C G 2$ inhibitors, but this would have led to the inclusion of rather inactive compounds. In addition, $\mathrm{IC}_{50}$ values above $10 \mu \mathrm{M}$ imply that the necessary test concentrations were much higher (up to $100 \mu \mathrm{M}$ or more). At these concentration ranges, compound-related assay interferences (e.g., solubility problems, solvent effects, short-term cell toxicity, fluorescence quenching, or unspecific binding) are much more likely to have occurred. Hence, compounds with activities above $10 \mu \mathrm{M}$ could not be considered as "active". However, it must also be stated that, due to the $10 \mu \mathrm{M}$ threshold, the value distribution after compound categorization and classification was rather unequal. This can be seen, for example, when comparing selective ABCG2 inhibitors (class 3) with 435 representatives, and dual $\mathrm{ABCB} 1$ and $\mathrm{ABCC} 1$ inhibitors (class 4) with 17 compounds. This mainly depended on the literature itself and could not be influenced.

The third major aspect was the data processing and the definition of selection criteria. A virtual hit rate of $62.5 \%$ is above average; however, the model was not able to predict all 48 triple $\mathrm{ABCB} 1, \mathrm{ABCC} 1$, and $\mathrm{ABCG} 2$ inhibitors, although its selection criteria were in part deduced from these. In terms of the selection criteria, it must generally be considered that selectivity and promiscuity are not discrete but continuous attributes of compounds. Statistically speaking, there is a fluent border between both attributes. Molecules consist mostly of several partial structures that for their part can independently or collectively interact with the target(s) leading to selectivity or promiscuity. This ambivalent characteristic of individual substructures can lead to the fact that these are present in both single- or multitarget inhibitors. Our aim was to define unambiguous selection criteria, or at least as close to this as possible. This explains why many substructures present in the triple inhibitors could not be acknowledged for the prediction of the very same triple inhibitors from the data set of 1049 compounds. Inclusion of these discriminated partial structures would inevitably have led to the prediction of more false positive hits and a decreased biological hit rate. To avoid a "randomization" of the model, we chose $15 \%$ as the threshold for the selection of clear positive hits. This threshold allowed for the selection of a sufficient number of substructures as clear positive hits. A higher percentage almost eliminates these clear positive hits, while a lower percentage results in the selection of less pronounced multitarget substructures (leading to more false positive hits). On the other hand, this number of $15 \%$ implies that the residual $85 \%$ of molecules contained dually active, selective, or even inactive compounds. This imbalance posed in our point of view the highest impact on the development of C@PA. Furthermore, novel scaffolds (Screen 5 ) were chosen that have never been reported before regarding the $\mathrm{ABC}$ transporters $\mathrm{ABCB} 1, \mathrm{ABCC} 1$, and $\mathrm{ABCG} 2$ according to the initial data set of 1049 compounds (Supplementary Table 4). Selecting for these 29 novel heteroaromatic scaffolds inherited per se a risk of lowering the biological hit rate. However, as the task of this investigation was to identify novel heteroaromatic scaffolds and molecules, stepping into this unknown territory was obligatory. Finally, the manual selection posed also a risk of faulty selection. As outlined above, these criteria were mainly based on our experience with $A B C$ transporter inhibitors. ${ }^{16,17,27-29,55} \mathrm{C} @ \mathrm{PA}$ benefited from these experience-driven decisions, as the following shows: (i) a strong focus was put on individual substituents like fluorine, chlorine, cyano, or methoxy, especially in combination. Strikingly, 6 of the 23 compounds had such a combination (17-18, 21, 26, 31, and 33), amongst these were three triple $\mathrm{ABCB} 1, \mathrm{ABCC} 1$, and $\mathrm{ABCG} 2$ inhibitors $(\mathbf{1 8}, \mathbf{2 1}$, and 26; $50.0 \%)$. More strikingly, almost all $(15,18,21$, and 26; 80.0\%) of the triple inhibitors had at least one of such a substructure. Moreover, when turning the focus on dual and triple (= multitarget) inhibitors of $\mathrm{ABC}$ transporters, $71.4 \%$ (10 out of 14) had at least one of these substructures; (ii) the partial structures piperazine (22), homo-piperazine (18), and piperidine (26) were reflected in the five multitarget $\mathrm{ABCB} 1$, ABCC1, and ABCG2 inhibitors (60.0\%); Hence, we conclude that the manual selection rather supported than impaired the model and contributed to the finding of multitarget $A B C B 1$, $\mathrm{ABCC} 1$, and $\mathrm{ABCG} 2$ inhibitors.

The fourth and final major aspect is the target variety. Multitarget inhibition was in the focus of the present study. As $\mathrm{ABCB} 1,{ }^{2} \mathrm{ABCC} 1,{ }^{3}$ and $\mathrm{ABCG} 2^{4}$ have their individual "preferences" regarding inhibitors, finding simultaneously interfering agents is quite an obstacle, which distinguishes $\mathrm{C} @ \mathrm{PA}$ from other approaches in the literature. ${ }^{67-71}$ Compound characteristics such as lipophilicity or MW can inversely correlate with the inhibition of the respective 
transporter, therefore exacerbating the finding of a multitarget inhibitor. This raised initially the question if a rational approach was possible at all to obtain novel multitarget $\mathrm{ABCB} 1, \mathrm{ABCC} 1$, and $\mathrm{ABCG} 2$ inhibitors.

Despite these multifaceted challenges, the model proved that it is generally possible to predict broad-spectrum $\mathrm{ABCB} 1$, $A B C C 1$, and $A B C G 2$ inhibitors after processing of literature data and identification of critical fingerprints. This cannot only be perceived from the finding of five novel multitarget $A B C B 1$, $A B C C 1$, and $A B C G 2$ inhibitors but also from the discovery of nine dual $A B C B 1$ and $A B C G 2$ inhibitors $(13,16,17,23-25$, 27, 30, and 32). Consequently, $60.9 \%$ of the selected 23 molecules were multitarget inhibitors of $\mathrm{ABC}$ transporters. Although dual inhibition was not in the scope of the present study, it must be acknowledged that these numbers mean that suitable molecular patterns were extracted for multitarget $A B C B 1, A B C C 1$, and $A B C G 2$ inhibition. In addition, two major achievements are that (i) the 1,2,4-oxadiazole moiety can be suggested as the seventh basic scaffold for triple $A B C B 1, A B C C 1$, and ABCG2 inhibition, and (ii) the fluorine, chlorine, methoxy, as well as cyano substructures, as well as the piperazine, homopiperazine, and piperidine linkers can, in association with multitarget $\mathrm{ABC}$ transporter inhibition, at least be considered as "secondary positive patterns". Both achievements complement the multitarget fingerprints and will be of use when improving C@PA's prediction capabilities (e.g., as C@PA_1.2).

$\mathrm{C} @ \mathrm{PA}$ provides the unique opportunity to shift the methodology to discover multitarget $\mathrm{ABCB} 1, \mathrm{ABCC} 1$, and ABCG2 inhibitors from "serendipity" to "rationale". Now, it is not a matter of luck anymore to gain novel multitarget inhibitors, but only of statistics, and C@PA proved also to be greatly efficient compared to other computational approaches, such as similarity search and pharmacophore modeling. Remarkably, considering that common motifs within the $\mathrm{ABC}$ transporter superfamily exist, C@PA provides also the unique chance to predict and discover novel agents that target understudied $A B C$ transporters that cannot be addressed by small-molecules until now. Finally, this methodology may be transferred to other protein families as well, thriving also drug development in other scientific areas in general.

\section{EXPERIMENTAL SECTION}

Computational Analysis. Compilation of Data Set and Categorization of Compounds. Literature research to find and assemble inactive, selective, dual, and triple inhibitors of the $\mathrm{ABC}$ transport proteins $\mathrm{ABCB} 1, \mathrm{ABCC} 1$, and $\mathrm{ABCG} 2$ was conducted using the National Center for Biotechnological Information (NCBI). ${ }^{72}$ Reports were only considered when they either presented simultaneous testing at $\mathrm{ABCB} 1, \mathrm{ABCC} 1$, and $\mathrm{ABCG} 2$, or the respective compound has been evaluated regarding $A B C B 1$, $A B C C 1$, and $A B C G 2$ in several individual reports. SMILES codes (isomeric if applicable) were either obtained from PubChem, ${ }^{72}$ manually assembled from associated content and supplementary material as provided by the respective report, or manually drawn according to the $2 \mathrm{D}$ representations provided by the corresponding report using ChemDraw Pro [version 17.1.0.105 (19)]. Determined $\mathrm{IC}_{50}$ values and deviations were assembled as reported in the respective literature under referral to the applied testing system (detection method and host system; Supplementary Table 1). In case the $\mathrm{IC}_{50}$ was needed to be estimated from relative inhibition data, the used concentration of the respective compound and its relative effect to a standard $\mathrm{ABCB} 1, \mathrm{ABCC} 1$, and $\mathrm{ABCG} 2$ inhibitor were taken into account to categorize the corresponding compound into "active" (estimated $\mathrm{IC}_{50}$ value $<10 \mu \mathrm{M}$ ) or "inactive" (estimated $\mathrm{IC}_{50}$ value $\geq 10 \mu \mathrm{M})$. In total, 1049 compounds from 93 reports between 2004 and 2020 were taken into account for further data processing. The associated original literature is also provided in Supplementary Table 1. For compound categorization, the assembled data in Supplementary Table 1 has been fused to associate one compound with one single $\mathrm{IC}_{50}$ value (Supplementary Table 2). In the case of two reported $\mathrm{IC}_{50}$ values or a given $\mathrm{IC}_{50}$ span, the mean was calculated. In case of defined and estimated $\mathrm{IC}_{50}$ values, the defined value has been given priority. In the case of activity ( $\mathrm{IC}_{50}$ present) and inactivity ( $\mathrm{IC}_{50}$ not present), the defined $\mathrm{IC}_{50}$ value was given priority. Compounds with $\mathrm{IC}_{50}$ values below $10 \mu \mathrm{M}$ were considered as active ( 1 , "one"), others as inactive ( 0 , "zero"). The data provided in Supplementary Table 2 was translated into a script (ABCB1, ABCC1, and ABCG2), and the compounds classified as follows: (i) class 0: 0 , 0 , 0; (ii) class 1: 1, 0, 0; (iii) class 2: $0,1,0$; (iv) class 3: 0, 0, 1; (v) class 4 : $1,1,0$; (vi) class $5: 1,0,1$; (vii) class $6: 0,1,1$; (viii) class 7 : 1, 1, 1 (Supplementary Table 3).

Basic Scaffold Search and Statistical Substructure Analysis. The Structure-Activity-Report (SAReport) tool $^{48}$ implemented in Molecular Operating Environment (MOE; version 2019.1) ${ }^{49}$ was used for the elucidation of the basic scaffolds of class 7 compounds. A total of 308 substructures $^{50}$ (Supplementary Table 4) were searched amongst the 1049 compounds using InstantJChem, ${ }^{51}$ and their absolute as well as relative distribution was calculated. The relative distribution was categorized into: (i) group A: percentage of class 0; (ii) group B: sum of percentages of classes 1-3; (iii) group C: sum of percentages of classes 4-6; (iv) group D: percentage of class 7; and (v) group E: sum of percentages of classes 4-7.

Identification of Multitarget Fingerprints. "Clear positive hits" as indicators for triple $\mathrm{ABCB} 1, \mathrm{ABCC} 1$, and $\mathrm{ABCG} 2$ inhibition were defined as follows: (i) the respective substructure must have appeared at least five times within the 1049 molecules; (ii) group D must be at least 15\%; and either (iii) group D must be at least equal to group B, or (iv) group E must be at least equal to group B. "Clear negative hits" were defined as follows: (i) the respective substructure must have appeared at least five times amongst the 1049 molecules; (ii) the respective substructure must not account for class 7 compounds (group D must be 0\%); and (iii) group B must be at least equal to group C.

Model Validation and Comparison to Common Computational Approaches. Model validation for C@PA has been conducted by applying Screen 2 ("Positive Pattern") and Screen 3 ("Negative Pattern") using a query search tool implemented in InstantJChem. ${ }^{51}$ The 2D similarity search was performed by using the MACCS fingerprints as implemented in MOE. ${ }^{49}$ This MACCS fingerprint contains 166 structural keys indicating the presence of specified structural fragments in the molecular graph representation. The similarity between the six selected query inhibitors $\mathbf{1}$ and $\mathbf{4 - 8}$ as well as the 1049 molecules in the dataset was measured by using a Tanimoto coefficient $(\mathrm{Tc})$ with a cutoff value of 0.8 . For the pharmacophore model, the six selected query inhibitors were aligned using the flexible alignment tool implemented in $\mathrm{MOE}^{49}$ as described before in detail. ${ }^{16}$ The best alignment was used to generate the pharmacophore model using the consensus methodology implemented in the Pharmacophore Query Editor. In total, 196,439 conformers for the 1049 molecules in the dataset were generated using the conformational search tool in $\mathrm{MOE}^{49}$ by applying the stochastic search method with a conformation limit of 10,000. The threshold for the identification of multitarget pharmacophore features was set at $50.0 \%$ and a tolerance value of 1.2 .

Virtual Screening, Selection Criteria, and Manual Candidate Selection. The ENAMINE Diverse REAL drug-like database was downloaded $^{52}$ and screened for compounds with (i) at least one basic scaffold, (ii) at least one clear positive hit, (iii) no clear negative hit, (iv) a $\log P$ and MW that stretched inside the span of class 7 compounds (LogP span: 2.4-6.9; MW span: 295-915), and (v) at least one "novel scaffold". LogP and MW were calculated using MOE (version 2019.01). ${ }^{49}$ In total 1505 potential candidates resulted, from which 87 were manually selected by experience-driven decisions depending on availability and price, from which 41 were ordered from 
ENAMINE and 23 were delivered within the purity requirement of $95 \%$. All compounds were screened for substructures present in panassay interference compounds (PAINS) and did not contain any of these motifs. ${ }^{73}$

The identities of compounds 11-14, 16-19, and 21-32 were determined by ENAMINE via ${ }^{1} \mathrm{H}$ NMR spectroscopy. Compounds 15, 20, and 33 were analyzed in our laboratory by using a Bruker Avance $500 \mathrm{MHz}(500 \mathrm{MHz})$. All NMR spectra were recorded in DMSO- $d_{6}$, and chemical shifts $(\delta)$ are expressed in ppm calibrated to the solvent signal of DMSO ( $\delta: 2.50 \mathrm{ppm})$. Spin multiplicities of compounds 11-33 are given as singlet (s), doublet (d), doublet of doublets $(\mathrm{dd})$, doublet of triplets $(\mathrm{dt})$, and multiplet $(\mathrm{m})$. The purity of compounds 11-33 was determined by ENAMINE via LC-MS analysis and stated as at least $96 \%$ pure. The complete analytical assessment of the compounds is provided in the Supporting Information.

3-(4-\{3,4-Dimethylthieno[2,3-b]pyridine-2-carbonyl\}piperazine1-carbonyl)-2H-indazole (11). ENAMINE ID: Z1001807112; ${ }^{1} \mathrm{H}$ NMR $\left(600 \mathrm{MHz}\right.$, DMSO- $\left.d_{6}\right) \delta: 13.55(\mathrm{~s}, 1 \mathrm{H}), 8.15-8.11(\mathrm{~m}, 1 \mathrm{H})$, $8.00-7.98(\mathrm{~m}, 1 \mathrm{H}), 7.63-7.58(\mathrm{~m}, 1 \mathrm{H}), 7.43-7.36(\mathrm{~m}, 1 \mathrm{H}), 7.24-$ $7.20(\mathrm{~m}, 1 \mathrm{H}), 4.30-3.40(\mathrm{~m}, 8 \mathrm{H}), 2.60(\mathrm{~s}, 3 \mathrm{H}), 2.35(\mathrm{~s}, 3 \mathrm{H})$; LC-MS $(m / z)$ calculated for $\mathrm{C}_{22} \mathrm{H}_{21} \mathrm{~N}_{5} \mathrm{O}_{2} \mathrm{~S}: 419.14$; found: $420.0[\mathrm{M}+1]^{+}$; purity: $100 \%$.

6-Methyl-N-[2-(5-propyl-1,2,4-oxadiazol-3-yl)propan-2-yl]quinoline-5-sulfonamide (12). ENAMINE ID: Z1137670336; ${ }^{1} \mathrm{H}$ NMR $\left(600 \mathrm{MHz}\right.$, DMSO- $\left.d_{6}\right) \delta: 9.25-9.20(\mathrm{~m}, 1 \mathrm{H}), 8.90-8.80(\mathrm{~m}$, $1 \mathrm{H}), 8.61(\mathrm{~s}, 1 \mathrm{H}), 8.10-8.05(\mathrm{~m}, 1 \mathrm{H}), 7.65-7.55(\mathrm{~m}, 2 \mathrm{H}), 2.73(\mathrm{~s}$, $3 \mathrm{H}), 2.48-2.43(\mathrm{~m}, 3 \mathrm{H}), 1.46(\mathrm{~s}, 6 \mathrm{H}), 1.43-1.35(\mathrm{~m}, 2 \mathrm{H}), 0.85-$ $0.78(\mathrm{~m}, 3 \mathrm{H})$; LC-MS $(\mathrm{m} / z)$ calculated for $\mathrm{C}_{18} \mathrm{H}_{22} \mathrm{~N}_{4} \mathrm{O}_{3} \mathrm{~S}$ : 374.14; found: $375.0[\mathrm{M}+1]^{+}$; purity: $100 \%$.

3-\{[4-(3-Methyl-1,2,4-thiadiazol-5-yl)-1,4-diazepan-1-yl]methyl\}2-(morpholin-4-yl)quinoline (13). ENAMINE ID: Z1569466770; ${ }^{1} \mathrm{H}$ NMR $\left(500 \mathrm{MHz}\right.$, DMSO- $\left.d_{6}\right) \delta: 8.11(\mathrm{~s}, 1 \mathrm{H}), 7.85-7.69(\mathrm{~m}, 2 \mathrm{H})$, $7.61-7.58(\mathrm{~m}, 1 \mathrm{H}), 7.41-7.35(\mathrm{~m}, 1 \mathrm{H}), 4.25-3.40(\mathrm{~m}, 10 \mathrm{H}), 3.25-$ $3.08(\mathrm{~m}, 4 \mathrm{H}), 2.90-2.78(\mathrm{~m}, 2 \mathrm{H}), 2.71-2.64(\mathrm{~m}, 2 \mathrm{H}), 2.30-2.15(\mathrm{~s}$, $3 \mathrm{H}), 1.98-1.78(\mathrm{~m}, 2 \mathrm{H})$; LC-MS $(\mathrm{m} / z)$ calculated for $\mathrm{C}_{22} \mathrm{H}_{28} \mathrm{~N}_{6} \mathrm{OS}$ : 424.20; found: $425.2[\mathrm{M}+1]^{+}$; purity: $100 \%$.

3,4-Dimethyl-N-\{4-[(1,3,4-thiadiazol-2-yl)sulfamoyl]phenyl\}thieno[2,3-b]pyridine-2-carboxamide (14). ENAMINE ID: Z1619753040; ${ }^{1} \mathrm{H}$ NMR (500 MHz, DMSO- $\left.d_{6}\right) \delta: 14.28(\mathrm{~s}, 1 \mathrm{H})$, $10.61(\mathrm{~s}, 1 \mathrm{H}), 8.70(\mathrm{~s}, 1 \mathrm{H}), 8.29-8.20(\mathrm{~m}, 1 \mathrm{H}), 7.95-7.71(\mathrm{~m}, 4 \mathrm{H})$, $7.45-7.35(\mathrm{~m}, 1 \mathrm{H}), 2.66-2.53(\mathrm{~m}, 6 \mathrm{H})$; LC-MS $(\mathrm{m} / z)$ calculated for $\mathrm{C}_{18} \mathrm{H}_{15} \mathrm{~N}_{5} \mathrm{O}_{3} \mathrm{~S}_{3}: 445.03$; found: $446.0[\mathrm{M}+1]^{+}$; purity: $98 \%$.

2,5-Dimethyl-4-\{[3-(3,4,5-trimethoxyphenyl)-1,2,4-oxadiazol-5yl]methoxy\}quinoline (15). ENAMINE ID: Z1815536867; ${ }^{1} \mathrm{H}$ NMR $\left(500 \mathrm{MHz}, \mathrm{DMSO}-d_{6}\right) \delta: 7.69(\mathrm{~d}, J=8.4 \mathrm{~Hz}, 1 \mathrm{H}), 7.53(\mathrm{dd}, J=8.4$, $7.1 \mathrm{~Hz}, 1 \mathrm{H}), 7.30(\mathrm{~s}, 2 \mathrm{H}), 7.26(\mathrm{dt}, J=7.0,1.2 \mathrm{~Hz}, 1 \mathrm{H}), 7.07(\mathrm{~s}, 1 \mathrm{H})$, $5.79(\mathrm{~s}, 2 \mathrm{H}), 3.86(\mathrm{~s}, 6 \mathrm{H}), 3.74(\mathrm{~s}, 3 \mathrm{H}), 2,86(\mathrm{~s}, 3 \mathrm{H}), 2.58(\mathrm{~s}, 3 \mathrm{H})$; LC-MS $(m / z)$ calculated for $\mathrm{C}_{23} \mathrm{H}_{23} \mathrm{~N}_{3} \mathrm{O}_{5}: 421.16$; found: $422.2[\mathrm{M}+$ $1]^{+}$; purity: $96 \%$.

5-Chloro-N-\{[3-(4-methylquinolin-2-yl)-1,2,4-oxadiazol-5-yl]methyl\}thiophene-2-sulfonamide (16). ENAMINE ID: Z1890912753; ${ }^{1} \mathrm{H}$ NMR (600 MHz, DMSO- $\left.d_{6}\right) \delta$ : 9.19 (s, $\left.1 \mathrm{H}\right)$, 8.23-8.11 (m, 2H), $7.96(\mathrm{~s}, 1 \mathrm{H}), 7.90-7.84(\mathrm{~m}, 1 \mathrm{H}), 7.78-7.73(\mathrm{~m}$, $1 \mathrm{H}), 7.54-7.50(\mathrm{~m}, 1 \mathrm{H}), 7.23-7.18(\mathrm{~m}, 1 \mathrm{H}), 4.60(\mathrm{~s}, 2 \mathrm{H}), 2.80(\mathrm{~s}$, $3 \mathrm{H})$; LC-MS $(\mathrm{m} / z)$ calculated for $\mathrm{C}_{17} \mathrm{H}_{13} \mathrm{ClN}_{4} \mathrm{O}_{3} \mathrm{~S}_{2}: 420.01$; found: $421.0[\mathrm{M}+1]^{+}$; purity: $100 \%$.

3-[(5-Chloro-1,3-dimethyl-1H-pyrazol-4-yl)methyl]-5-[3-methyl6-(trifluoromethyl)thieno[2,3-b]pyridin-2-yl]-1,2,4-oxadiazole (17). ENAMINE ID: Z1891639106; ${ }^{1} \mathrm{H}$ NMR $\left(600 \mathrm{MHz}, \mathrm{DMSO}-d_{6}\right) \delta$ : 8.80-8.75 (m, 1H), 8.10-8.05 (m, 1H), $7.96(\mathrm{~s}, 1 \mathrm{H}), 3.95(\mathrm{~s}, 2 \mathrm{H})$, $3.70(\mathrm{~s}, 3 \mathrm{H}), 2.85(\mathrm{~s}, 3 \mathrm{H}), 2.16(\mathrm{~s}, 3 \mathrm{H})$; LC-MS $(\mathrm{m} / \mathrm{z})$ calculated for $\mathrm{C}_{17} \mathrm{H}_{13} \mathrm{ClF}_{3} \mathrm{~N}_{5} \mathrm{OS}$ : 427.05 ; found: $428.0[\mathrm{M}+1]^{+}$; purity: $98 \%$.

6-(Propan-2-yl)-4-\{4-[5-(trifluoromethyl)-1,3,4-thiadiazol-2-yl]1,4-diazepan-1-yl\}quinoline-3-carbonitrile (18). ENAMINE ID: Z1896692207; ${ }^{1} \mathrm{H}$ NMR $\left(600 \mathrm{MHz}, \mathrm{DMSO}-d_{6}\right) \delta: 8.80(\mathrm{~s}, 1 \mathrm{H})$, 7.98-7.93 (m, 1H), 7.80-7.75 (m, 2H), 4.08-4.00 (m, 2H), 3.96$3.83(\mathrm{~m}, 4 \mathrm{H}), 3.68-3.63(\mathrm{~m}, 2 \mathrm{H}), 3.05-2.95(\mathrm{~m}, 1 \mathrm{H}), 2.25-2.18$ $(\mathrm{m}, 2 \mathrm{H}), 1.25-1.18(\mathrm{~m}, 6 \mathrm{H})$; LC-MS $(\mathrm{m} / \mathrm{z})$ calculated for $\mathrm{C}_{21} \mathrm{H}_{21} \mathrm{~F}_{3} \mathrm{~N}_{6} \mathrm{~S}$ : 446.15 ; found: $447.0[\mathrm{M}+1]^{+}$; purity: $100 \%$.
3-[3-(Furan-3-yl)-1,2,4-oxadiazol-5-yl]-N-(propan-2-yl)-N-(quinolin-3-yl)propanamide (19). ENAMINE ID: Z1933909500; ${ }^{1} \mathrm{H}$ NMR $\left(600 \mathrm{MHz}, \mathrm{DMSO}-d_{6}\right) \delta: 8.80(\mathrm{~s}, 1 \mathrm{H}), 8.43-8.33(\mathrm{~m}, 2 \mathrm{H})$, $8.13-8.05(\mathrm{~m}, 2 \mathrm{H}), 7.90-7.80(\mathrm{~m}, 2 \mathrm{H}), 7.73-7.65(\mathrm{~m}, 1 \mathrm{H}), 6.88(\mathrm{~s}$, $1 \mathrm{H}), 4.95-4.85(\mathrm{~m}, 1 \mathrm{H}), 3.13-3.03(\mathrm{~m}, 2 \mathrm{H}), 2.45-2.35(\mathrm{~m}, 2 \mathrm{H})$ $1.25-0.80(\mathrm{~m}, 6 \mathrm{H})$; LC-MS $(\mathrm{m} / z)$ calculated for $\mathrm{C}_{21} \mathrm{H}_{20} \mathrm{~N}_{4} \mathrm{O}_{3}$ : 376.15; found: $377.0[\mathrm{M}+1]^{+}$; purity: $100 \%$.

$N$-Methyl-N-(quinolin-8-yl)thieno[3,2-b]pyridine-6-sulfonamide (20). ENAMINE ID: Z1990107654; ${ }^{1} \mathrm{H}$ NMR $\left(500 \mathrm{MHz}\right.$, DMSO- $\left.d_{6}\right)$ $\delta: 8.83(\mathrm{dd}, J=2.1,0.8 \mathrm{~Hz}, 1 \mathrm{H}), 8.71(\mathrm{~d}, J=2.1 \mathrm{~Hz}, 2 \mathrm{H}), 8.43(\mathrm{~d}, J=$ $5.5 \mathrm{~Hz}, 2 \mathrm{H}), 8.37(\mathrm{dd}, J=8.3,1.7 \mathrm{~Hz}, 1 \mathrm{H}), 8.28(\mathrm{dd}, J=4.1,1.7 \mathrm{~Hz}$, $1 \mathrm{H}), 8.02(\mathrm{dd}, J=8.2,1.4 \mathrm{~Hz}, 1 \mathrm{H}), 7.77(\mathrm{dd}, J=7.4,1.4 \mathrm{~Hz}, 1 \mathrm{H})$, $7.67(\mathrm{dd}, J=5.5,0.8 \mathrm{~Hz}, 1 \mathrm{H}), 7.65(\mathrm{dd}, J=8.2,7.4 \mathrm{~Hz}, 1 \mathrm{H}), 7.40$ $(\mathrm{dd}, J=8.3,4.1 \mathrm{~Hz}, 1 \mathrm{H}), 3.45(\mathrm{~s}, 3 \mathrm{H})$; LC-MS $(\mathrm{m} / \mathrm{z})$ calculated for $\mathrm{C}_{17} \mathrm{H}_{13} \mathrm{~N}_{3} \mathrm{O}_{2} \mathrm{~S}_{2}$ : 355.04; found: $356.1[\mathrm{M}+1]^{+}$; purity: $100 \%$.

6-Methoxy-N-(propan-2-yl)- $N$ - $\{[3$-(pyridin-3-yl)-1,2,4-oxadiazol5-yl]methyl\}-2-(trifluoromethyl)quinazolin-4-amine (21). ENAMINE ID: Z2142862400; ${ }^{1} \mathrm{H}$ NMR $\left(500 \mathrm{MHz}, \mathrm{DMSO}-d_{6}\right) \delta$ : $9.03(\mathrm{~s}, 1 \mathrm{H}), 8.78-8.73(\mathrm{~m}, 1 \mathrm{H}), 8.30-8.21(\mathrm{~m}, 1 \mathrm{H}), 7.94-7.88(\mathrm{~m}$, $1 \mathrm{H}), 7.65-7.54(\mathrm{~m}, 2 \mathrm{H}), 7.44(\mathrm{~s}, 1 \mathrm{H}), 5.18(\mathrm{~s}, 2 \mathrm{H}), 4.98-4.88(\mathrm{~m}$, $1 \mathrm{H}), 2.94(\mathrm{~s}, 3 \mathrm{H}), 1.53-1.40(\mathrm{~m}, 6 \mathrm{H})$; LC-MS $(\mathrm{m} / z)$ calculated for $\mathrm{C}_{21} \mathrm{H}_{19} \mathrm{~F}_{3} \mathrm{~N}_{6} \mathrm{O}_{2}$ : 444.15; found: $445.0[\mathrm{M}+1]^{+}$; purity: $99 \%$.

2-Methyl-8-[(4-\{thieno[3,2-c]pyridin-4-yl\}piperazin-1-yl)sulfonyl]quinoline (22). ENAMINE ID: Z2145689641; ${ }^{1} \mathrm{H}$ NMR $\left(500 \mathrm{MHz}, \mathrm{DMSO}-d_{6}\right) \delta: 8.43-8.33(\mathrm{~m}, 2 \mathrm{H}), 8.28-8.21(\mathrm{~m}, 1 \mathrm{H})$, $7.99-7.93(\mathrm{~m}, 1 \mathrm{H}), 7.74-7.65(\mathrm{~m}, 2 \mathrm{H}), 7.59-7.43(\mathrm{~m}, 3 \mathrm{H}), 3.61-$ $3.49(\mathrm{~m}, 4 \mathrm{H}), 3.48-3.38(\mathrm{~m}, 4 \mathrm{H}), 2.71(\mathrm{~s}, 3 \mathrm{H})$; LC-MS $(\mathrm{m} / z)$ calculated for $\mathrm{C}_{21} \mathrm{H}_{20} \mathrm{~N}_{4} \mathrm{O}_{2} \mathrm{~S}_{2}: 424.10$; found: $425.0[\mathrm{M}+1]^{+}$; purity: $100 \%$.

2-[(7-Chloroquinolin-4-yl)sulfanyl]-N-(1-\{5-[(propan-2-yloxy)methyl]-1,2,4-oxadiazol-3-yl\}ethyl)propenamide (23). ENAMINE ID: Z2184940497; ${ }^{1} \mathrm{H}$ NMR (600 MHz, DMSO- $\left.d_{6}\right) \delta$ : 9.15-8.93 (m, $1 \mathrm{H}), 8.80-8.70(\mathrm{~m}, 1 \mathrm{H}), 8.15-8.03(\mathrm{~m}, 2 \mathrm{H}), 7.70-7.63(\mathrm{~m}, 1 \mathrm{H})$, $7.53-7.43(\mathrm{~m}, 1 \mathrm{H}), 5.10-5.00(\mathrm{~m}, 1 \mathrm{H}), 4.70(\mathrm{~s}, 2 \mathrm{H}), 4.40-4.30(\mathrm{~m}$, $1 \mathrm{H})$, $3.75-3.65(\mathrm{~m}, 1 \mathrm{H}), 1.60-1.35(\mathrm{~m}, 6 \mathrm{H}), 1.18-1.08(\mathrm{~m}, 6 \mathrm{H})$; LC-MS $(m / z)$ calculated for $\mathrm{C}_{20} \mathrm{H}_{23} \mathrm{ClN}_{4} \mathrm{O}_{3} \mathrm{~S}$ : 434.12; found: 435.0 $[\mathrm{M}+1]^{+}$; purity: $100 \%$.

$N^{4}$-(2,4-Dimethoxyphenyl)- $N^{6}-\{2-[5-($ propan-2-yl)-1,3,4-thiadiazol-2-yl]ethyl\}pyrimidine-4,6-diamine (24). ENAMINE ID: Z2199974094; ${ }^{1} \mathrm{H}$ NMR (500 MHz, DMSO- $\left.d_{6}\right) \delta: 7.98(\mathrm{~s}, 1 \mathrm{H})$, $7.80(\mathrm{~s}, 1 \mathrm{H}), 7.39-7.31(\mathrm{~m}, 1 \mathrm{H}), 6.91-6.83(\mathrm{~m}, 1 \mathrm{H}), 6.60(\mathrm{~s}, 1 \mathrm{H})$, 6.51-6.45 (m, 1H), $5.46(\mathrm{~s}, 1 \mathrm{H}), 3.80-3.69(\mathrm{~m}, 6 \mathrm{H}), 3.56-3.45(\mathrm{~m}$, $2 \mathrm{H}), 3.43-3.33(\mathrm{~m}, 1 \mathrm{H}), 3.25-3.20(\mathrm{~m}, 2 \mathrm{H}), 1.35-1.24(\mathrm{~m}, 6 \mathrm{H})$; LC-MS $(\mathrm{m} / z)$ calculated for $\mathrm{C}_{19} \mathrm{H}_{24} \mathrm{~N}_{6} \mathrm{O}_{2} \mathrm{~S}: 400.17$; found: $401.0[\mathrm{M}$ $+1]^{+}$; purity: $98 \%$.

$N^{4}$-Ethyl- $N^{4}$-phenyl- $N^{6}-\{2-[5-($ propan-2-yl)-1,3,4-thiadiazol-2-yl]ethyl\}pyrimidine-4,6-diamine (25). ENAMINE ID: Z2214001359; ${ }^{1} \mathrm{H}$ NMR $\left(600 \mathrm{MHz}\right.$, DMSO- $\left.d_{6}\right) \delta: 8.08(\mathrm{~s}, 1 \mathrm{H}), 7.49-7.43(\mathrm{~m}, 2 \mathrm{H})$, $7.33-7.28(\mathrm{~m}, 1 \mathrm{H}), 7.26-7.21(\mathrm{~m}, 2 \mathrm{H}), 6.88-6.80(\mathrm{~m}, 1 \mathrm{H}), 5.18(\mathrm{~s}$, $1 \mathrm{H}), 3.90-3.83(\mathrm{~m}, 2 \mathrm{H}), 3.55-3.43(\mathrm{~m}, 2 \mathrm{H}), 3.40-3.30(\mathrm{~m}, 1 \mathrm{H})$, $3.20-3.15(\mathrm{~m}, 2 \mathrm{H}), 1.35-1.25(\mathrm{~m}, 6 \mathrm{H}), 1.10-1.03(\mathrm{~m}, 3 \mathrm{H})$; LC-MS $(\mathrm{m} / z)$ calculated for $\mathrm{C}_{19} \mathrm{H}_{24} \mathrm{~N}_{6} \mathrm{~S}: 368.18$; found: $369.0[\mathrm{M}+1]^{+}$; purity: $100 \%$.

6-Methoxy-4-(4-\{[3-(propan-2-yl)-1,2,4-oxadiazol-5-yl]methyl\}piperidin-1-yl)quinoline-3-carbonitrile (26). ENAMINE ID: Z2434240495; ${ }^{1} \mathrm{H}$ NMR $\left(600 \mathrm{MHz}, \mathrm{DMSO}-d_{6}\right) \delta: 8.60(\mathrm{~s}, 1 \mathrm{H})$, $7.91-7.89(\mathrm{~m}, 1 \mathrm{H}), 7.51-7.48(\mathrm{~m}, 1 \mathrm{H}), 7.26-7.20(\mathrm{~m}, 1 \mathrm{H}), 3.90(\mathrm{~s}$ $3 \mathrm{H}), 3.81-3.75(\mathrm{~m}, 2 \mathrm{H}), 3.46-3.38(\mathrm{~m}, 2 \mathrm{H}), 3.09-3.00(\mathrm{~m}, 1 \mathrm{H})$, $3.00-2.98(\mathrm{~m}, 2 \mathrm{H}), 2.20-2.11(\mathrm{~m}, 1 \mathrm{H}), 1.94-1.83(\mathrm{~m}, 2 \mathrm{H}), 1.68-$ $1.58(\mathrm{~m}, 2 \mathrm{H}), 1.30-1.19(\mathrm{~m}, 6 \mathrm{H})$; LC-MS $(\mathrm{m} / \mathrm{z})$ calculated for $\mathrm{C}_{22} \mathrm{H}_{25} \mathrm{~N}_{5} \mathrm{O}_{2}$ : 391.20; found: $392.3[\mathrm{M}+1]^{+}$; purity: $100 \%$.

6-[3-(1-Methyl-1H-indol-3-yl)-1,2,4-oxadiazol-5-yl]-N-phenylpyrimidin-4-amine (27). ENAMINE ID: Z2902917812; ${ }^{1} \mathrm{H}$ NMR $(600$ $\left.\mathrm{MHz}, \mathrm{DMSO}-d_{6}\right) \delta: 10.13(\mathrm{~s}, 1 \mathrm{H}), 8.83(\mathrm{~s}, 1 \mathrm{H}), 8.20(\mathrm{~s}, 1 \mathrm{H}), 8.15-$ $8.08(\mathrm{~m}, 1 \mathrm{H}), 7.80-7.58(\mathrm{~m}, 4 \mathrm{H}), 7.43-7.25(\mathrm{~m}, 4 \mathrm{H}), 7.15-7.05$ $(\mathrm{m}, 1 \mathrm{H}), 3.91(\mathrm{~s}, 3 \mathrm{H})$; LC-MS $(\mathrm{m} / z)$ calculated for $\mathrm{C}_{21} \mathrm{H}_{16} \mathrm{~N}_{6} \mathrm{O}$ : 368.14; found: $369.0[\mathrm{M}+1]^{+}$; purity: $100 \%$.

8-Methoxy- $N$ - $\{2-[5$-(propan-2-yl)-1,3,4-thiadiazol-2-yl]ethyl\}quinazolin-4-amine (28). ENAMINE ID: Z3019339476; ${ }^{1} \mathrm{H}$ NMR $\left(600 \mathrm{MHz}, \mathrm{DMSO}-d_{6}\right) \delta: 8.43(\mathrm{~s}, 1 \mathrm{H}), 8.40-8.30(\mathrm{~m}, 1 \mathrm{H}), 7.73-$ $7.65(\mathrm{~m}, 1 \mathrm{H}), 7.48-7.40(\mathrm{~m}, 1 \mathrm{H}), 7.28-7.20(\mathrm{~m}, 1 \mathrm{H}), 3.98-3.85$ 
(m, $4 \mathrm{H}), 3.50-3.40(\mathrm{~m}, 2 \mathrm{H}), 3.40-3.34(\mathrm{~m}, 2 \mathrm{H}), 1.38-1.25(\mathrm{~m}$, $6 \mathrm{H})$; LC-MS $(\mathrm{m} / z)$ calculated for $\mathrm{C}_{16} \mathrm{H}_{19} \mathrm{~N}_{5} \mathrm{OS}: 329.13$; found: 330.0 $[\mathrm{M}+1]^{+}$; purity: $96 \%$.

N-(7,8-Difluoroquinolin-3-yl)-4-(propan-2-yl)-1,2,3-thiadiazole5-carboxamide (29). ENAMINE ID: Z4595013321; ${ }^{1} \mathrm{H}$ NMR (500 MHz, DMSO- $\left.d_{6}\right) \delta: 11.35(\mathrm{~s}, 1 \mathrm{H}), 9.10-9.01(\mathrm{~m}, 1 \mathrm{H}), 8.98-8.85$ (m, 1H), 7.99-7.89 (m, 1H), 7.80-7.69 (m, 1H), 3.74-3.61 (m, $1 \mathrm{H}), \quad 1.49-1.35(\mathrm{~m}, 6 \mathrm{H})$; LC-MS $(\mathrm{m} / \mathrm{z})$ calculated for $\mathrm{C}_{15} \mathrm{H}_{12} \mathrm{FN}_{5} \mathrm{OS}$ : 334.07; found: $335.0[\mathrm{M}+1]^{+}$; purity: $100 \%$.

7,8-Difluoro-N-[1-(propan-2-yl)-1H-indazol-5-yl]quinazolin-4amine (30). ENAMINE ID: Z4595013374; ${ }^{1} \mathrm{H}$ NMR (500 MHz, DMSO-d $\left.d_{6}\right) \delta: 10.10(\mathrm{~s}, 1 \mathrm{H}), 8.55(\mathrm{~s}, 1 \mathrm{H}), 8.48-8.40(\mathrm{~m}, 1 \mathrm{H}), 8.10$ (s, 1H), $8.06(\mathrm{~s}, 1 \mathrm{H}), 7.79-7.66(\mathrm{~m}, 2 \mathrm{H}), 7.66-7.60(\mathrm{~m}, 1 \mathrm{H}), 5.05-$ $4.95(\mathrm{~m}, 1 \mathrm{H}), 1.55-1.40(\mathrm{~m}, 6 \mathrm{H})$; LC-MS $(\mathrm{m} / \mathrm{z})$ calculated for $\mathrm{C}_{18} \mathrm{H}_{15} \mathrm{~F}_{2} \mathrm{~N}_{5}$ : 339.13; found: $340.2[\mathrm{M}+1]^{+}$; purity: $100 \%$.

3-(3-Chloro-2-methoxyphenyl)-5-\{thieno[2,3-b]pyridin-5-yl\}1,2,4-oxadiazole (31). ENAMINE ID: Z4595013397; ${ }^{1} \mathrm{H}$ NMR (600 MHz, DMSO- $\left.d_{6}\right) \delta: 9.30(\mathrm{~s}, 1 \mathrm{H}), 9.09(\mathrm{~s}, 1 \mathrm{H}), 8.11-8.08(\mathrm{~m}, 1 \mathrm{H})$, 8.03-7.99 (m, 1H), 7.80-7.75 (m, 1H), 7.70-7.65 (m, 1H), 7.43$7.36(\mathrm{~m}, 1 \mathrm{H}), 3.90(\mathrm{~s}, 3 \mathrm{H})$; LC-MS $(\mathrm{m} / z)$ calculated for $\mathrm{C}_{16} \mathrm{H}_{10} \mathrm{ClN}_{3} \mathrm{O}_{2} \mathrm{~S}$ : 343.02 ; found: $344.0[\mathrm{M}+1]^{+}$; purity: $96 \%$.

8-Fluoro-3-(5-\{[1-(propan-2-yl)-1H-pyrazol-3-yl]methyl\}-1,2,4oxadiazol-3-yl)quinoline (32). ENAMINE ID: Z4595013410; ${ }^{1} \mathrm{H}$ NMR $\left(600 \mathrm{MHz}, \mathrm{DMSO}-d_{6}\right) \delta: 9.48(\mathrm{~s}, 1 \mathrm{H}), 9.10(\mathrm{~s}, 1 \mathrm{H}), 8.10-8.03$ (m, $1 \mathrm{H}), 7.80-7.63(\mathrm{~m}, 3 \mathrm{H}), 6.30-6.23(\mathrm{~m}, 1 \mathrm{H}), 4.50-4.40(\mathrm{~m}$, $3 \mathrm{H}), 1.45-1.35(\mathrm{~m}, 6 \mathrm{H})$; LC-MS $(\mathrm{m} / z)$ calculated for $\mathrm{C}_{18} \mathrm{H}_{16} \mathrm{FN}_{5} \mathrm{O}$ : 337.13; found: $338.2[\mathrm{M}+1]^{+}$; purity: $100 \%$.

3-Chloro-N-[3-(methylsulfanyl)-1,2,4-thiadiazol-5-yl]thieno[2,3b]pyridine-2-carboxamide (33). ENAMINE ID: Z4595013450; ${ }^{1} \mathrm{H}$ NMR $\left(500 \mathrm{MHz}, \mathrm{DMSO}-d_{6}\right) \delta: 13.81(\mathrm{~s}, 1 \mathrm{H}), 8.82(\mathrm{dd}, J=4.6,1.6$ $\mathrm{Hz}, 1 \mathrm{H}), 8.38(\mathrm{~d}, J=8.2 \mathrm{~Hz}, 1 \mathrm{H}), 7.67(\mathrm{dd}, J=8.2,4.6 \mathrm{~Hz}, 1 \mathrm{H}), 2.60$ $(\mathrm{s}, 3 \mathrm{H})$; LC-MS $(\mathrm{m} / z)$ calculated for $\mathrm{C}_{11} \mathrm{H}_{7} \mathrm{ClN}_{4} \mathrm{OS}_{3}$ : 341.95 ; found: $343.0[\mathrm{M}+1]^{+}$; purity: $100 \%$.

Biological Investigation. Materials. Cyclosporine A and compound 34 were obtained from Tocris Bioscience (Bristol, UK). Calcein AM and pheophorbide A were purchased from Calbiochem [EMD Chemicals (San Diego, USA), supplied by Merck KgaA (Darmstadt, Germany)]. Other chemicals were delivered by Carl Roth (Karlsruhe, Germany), Merck KgaA (Darmstadt, Germany), or Sigma-Aldrich (Taufkirchen, Germany). Ten millimolar DMSO stock solutions of cyclosporine A, compound 34, and compounds 11-33 were prepared and stored at $-20{ }^{\circ} \mathrm{C}$. Dilution series of the respective compounds and in-experiment cell culture was performed with KrebsHEPES buffer [KHB; $118.6 \mathrm{mM} \mathrm{NaCl}, 4.7 \mathrm{mM} \mathrm{KCl}, 1.2 \mathrm{mM}$ $\mathrm{KH}_{2} \mathrm{PO}_{4}, 4.2 \mathrm{mM} \mathrm{NaHCO}, 1.3 \mathrm{mM} \mathrm{CaCl}, 1.2 \mathrm{mM} \mathrm{MgSO} 4,11.7$ $\mathrm{mM}$ D-glucose monohydrate, $10.0 \mathrm{mM}$ HEPES (2-[4-(2hydroxyethyl)piperazin-1-yl] ethanesulfonic acid) in doubly distilled water; adjusted to $\mathrm{pH} 7.4$ with $\mathrm{NaOH}$; sterilized with $0.2 \mu \mathrm{m}$ membrane filters].

Cell Culture. A2780/ADR cells were delivered by European Collection of Animal Cell Culture (ECACC, no. 93112520) and cultured with RPMI-1640 medium (PAN-Biotech GmbH, Aidenbach, Germany) supplemented with $10 \%$ fetal bovine serum (FCS; PANBiotech $\mathrm{GmbH}$, Aidenbach, Germany), $50 \mu \mathrm{g} / \mu \mathrm{L}$ streptomycin (PAN-Biotech $\mathrm{GmbH}$, Aidenbach, Germany), $50 \mathrm{U} / \mathrm{mL}$ penicillin G (PAN-Biotech GmbH, Aidenbach, Germany), and $2 \mathrm{mM} \mathrm{L}-$ glutamine (PAN-Biotech GmbH, Aidenbach, Germany). H69AR cells were provided by American Type Culture Collection (ATCC CRL11351) and cultivation was performed using RPMI-1640 medium supplemented with $20 \% \mathrm{FCS}, 50 \mu \mathrm{g} / \mu \mathrm{L}$ streptomycin, $50 \mathrm{U} / \mathrm{mL}$ penicillin G, and $2 \mathrm{mM}$ L-glutamine. MDCK II BCRP cells were a generous gift from Dr. A. Schinkel (The Netherlands Cancer Institute, Amsterdam, The Netherlands) $)^{74}$ and cultured in Dulbecco's modified eagle medium (DMEM; Sigma Life Science, Steinheim, Germany) supplemented with $10 \%$ FCS, $50 \mu \mathrm{g} / \mu \mathrm{L}$ streptomycin, $50 \mathrm{U} / \mathrm{mL}$ penicillin $\mathrm{G}$, and $2 \mathrm{mM}$ L-glutamine. Cells were stored under liquid nitrogen in medium (90\%) and DMSO (10\%) before culturing (5\% $\mathrm{CO}_{2}$-humidified atmosphere; $37^{\circ} \mathrm{C}$ ). Cell harvesting was performed at a confluence of at least $90 \%$ by exposure to a trypsin $(0.05 \%)$ EDTA $(0.02 \%)$ solution (PAN-Biotech $\mathrm{GmbH}$, Aidenbach, Ger- many). Cells were subsequently collected, centrifuged in a $50 \mathrm{~mL}$ falcon (Greiner Bio-One, Frickenhausen, Germany) at $266 g, 4{ }^{\circ} \mathrm{C}, 4$ min (Avanti J-25, Beckmann Coulter, Krefeld, Germany), supernatant removal and resuspension in fresh media, counted (CASY TT cell counter with $150 \mu \mathrm{m}$ capillary, Schärfe System GmbH, Reutlingen, Germany), and seeded in right amount for sub-culturing or biological testing.

Calcein AM Assay. Calcein AM assays to assess inhibitory activity against $\mathrm{ABCB} 1$ and $\mathrm{ABCC} 1$ were applied as described earlier. ${ }^{14-16,56}$ Twenty micromolar of either 50 or $100 \mu \mathrm{M}$ of compounds 11-33 were added to a 96-well flat-bottom clear plate (Greiner, Frickenhausen, Germany) and complemented with $160 \mu \mathrm{L}$ of cell suspension containing either A2780/ADR or H69AR cells at a density of 30,000 and 60,000 cells/well, respectively. After incubation (5\% $\mathrm{CO}_{2}$-humidified atmosphere; $\left.37^{\circ} \mathrm{C}\right)$ for $30 \mathrm{~min}$, calcein $\mathrm{AM}(3.125$ $\mu \mathrm{M} ; 20 \mu \mathrm{L}$ ) was added to each well followed by immediate measurement of fluorescence increase (excitation: $485 \mathrm{~nm}$; emission: $520 \mathrm{~nm}$; interval: $60 \mathrm{~s}$; duration: $1 \mathrm{~h}$ ) using POLARstar and FLUOstar Optima microplate readers (BMG Labtech, software versions 2.00R2/2.20 and 4.11-0; Offenburg, Germany). Slopes from the linear fluorescence increase were calculated and compared to the respective slopes of the standard inhibitors. To determine $\mathrm{IC}_{50}$ values, in-depth concentration-effect curves have been generated by plotting the slopes against several logarithmic concentrations of the tested compounds. Data analysis was performed using GraphPad Prism (version 8.4.0, San Diego, CA, USA) using the statistically preferred model (three- or four-parameter logistic equation).

Pheophorbide A Assay. The pheophorbide A assay to assess inhibitory activity against ABCG2 was applied as described earlier. ${ }^{14-16}$ Compound and cell preparation was conducted as described above. In total, 45,000 cells in a $160 \mu \mathrm{L}$ suspension were pipetted into flat-bottom clear 96-well plates after $20 \mu \mathrm{L}$ of the respective compound dilution has been added (Thermo Scientific, Rochester, NY, USA). A pheophorbide A solution $(20 \mu \mathrm{L} ; 5 \mu \mathrm{M})$ was supplemented, and the reaction mixture was incubated for $120 \mathrm{~min}$ $\left(5 \% \mathrm{CO}_{2}\right.$-humidified atmosphere; $\left.37^{\circ} \mathrm{C}\right)$. Eventually, the intracellular fluorescence was detected via flow cytometry (Guava easyCyte HT, Merck Millipore, Billerica, MA, USA) at an excitation wavelength of $488 \mathrm{~nm}$ and emission wavelength of $695 / 50 \mathrm{~nm}$. The absolute fluorescence values were compared to the effect caused by the standard ABCG2 inhibitor compound 34. Determination of relative inhibition and $\mathrm{IC}_{50}$ values were determined as described above.

Hoechst 33342 Assay. To confirm the inhibitory effect of compounds 15, 18, 21, 22, and 26 against ABCB1 and ABCG2, as well as compound 27 against ABCG2, a Hoechst 33342 assay was performed as described earlier. ${ }^{15,57}$ Twenty microliters of the dilutions of the compounds in KHB were pipetted into black 96-well plates (Greiner, Frickenhausen, Germany). Cells were processed as described before, and approximately 30,000 were seeded into the plates with $160 \mu \mathrm{L}$ per well. After a $30 \mathrm{~min}$ incubation period at $37^{\circ} \mathrm{C}$ and $5 \% \mathrm{CO}_{2}$, Hoechst 33342 solution $(10 \mu \mathrm{M})$ was added at a quantity of $20 \mu \mathrm{L}$ resulting in a final Hoechst 33342 concentration of $1 \mu \mathrm{M}$. Fluorescence intensity was assessed in $60 \mathrm{~s}$ time intervals for a time period of $120 \mathrm{~min}$ at an excitation wavelength of $355 \mathrm{~nm}$ and an emission wavelength of $460 \mathrm{~nm}$ using microplate readers (POLARstar and FLUOstar Optima by BMG Labtech, Offenburg, Germany). The average fluorescence values at the steady state were calculated for each concentration and plotted against the logarithm of the compound concentration. Determination of relative inhibition and $\mathrm{IC}_{50}$ values were determined as described above.

Daunorubicin Accumulation Assay. For further confirmation of the inhibitory potency of triple inhibitors on $\mathrm{ABCC} 1$, daunorubicin accumulation assay was applied as described before with minor modifications. Dilution series of test compounds and cell culture were performed as described for the calcein AM assay. To $20 \mu \mathrm{L}$ of the test compounds in different concentrations in a clear flat-bottom 96-well plate (Thermo Scientific, Waltham, MA, USA), $160 \mu \mathrm{L}$ of the cell suspension containing approximately 45,000 H69 AR cells in colorless culture medium without supplements was added. Then, $20 \mu \mathrm{L}$ of a 30 $\mu \mathrm{M}$ daunorubicin solution were pipetted to the mixture and incubated 
for 180 min protected from light at $37^{\circ} \mathrm{C}$ and a $5 \% \mathrm{CO}_{2}$ humidified atmosphere. Fluorescence was measured by flow cytometry (Guava easyCyte HT) at a $488 \mathrm{~nm}$ excitation wavelength and 695/50 nm emission wavelength. Data analysis was performed as described before. Determination of relative inhibition and $\mathrm{IC}_{50}$ values were determined as described above.

\section{ASSOCIATED CONTENT}

\section{(s) Supporting Information}

The Supporting Information is available free of charge at https://pubs.acs.org/doi/10.1021/acs.jmedchem.0c02199.

The complete dataset of categorized and classified 1049 compounds (Supplementary Tables 1-3); statistical analysis of substructure search (Supplementary Table 4 ); and molecular formula strings of "Screen 5" compounds before manual selection (Supplementary Table 5) (ZIP)

Molecular formula strings and the biological data of compounds 11-33 (Supplementary Table 6) (CSV)

Concentration-effect curves of compound 15 against $\mathrm{ABCB} 1$ ( $\mathrm{A}$ and $\mathrm{D}$ ), $\mathrm{ABCC} 1$ (B and $\mathrm{E}$ ), and ABCG2 (C and $F$ ) as determined in calcein $A M$ ( $A$ and $B$ ), pheophorbide A (C), Hoechst 33342 (D and F), and daunorubicin (E) assays (Supplementary Figure 1 A$\mathrm{F})$; concentration-effect curves of compound 18 against $\mathrm{ABCB} 1$ ( $\mathrm{A}$ and $\mathrm{D}$ ), $\mathrm{ABCC} 1$ (B and $\mathrm{E}$ ), and ABCG2 (C and $F$ ) as determined in calcein $A M$ ( $A$ and $B$ ), pheophorbide A (C), Hoechst 33342 (D and F), and daunorubicin (E) assays (Supplementary Figure 2 A$\mathrm{F})$; concentration-effect curves of compound 22 against $\mathrm{ABCB} 1$ ( $\mathrm{A}$ and $\mathrm{D}$ ), $\mathrm{ABCC} 1$ (B and $\mathrm{E}$ ), and ABCG2 (C and $\mathrm{F}$ ) as determined in calcein $\mathrm{AM}$ ( $\mathrm{A}$ and $\mathrm{B}$ ), pheophorbide A (C), Hoechst 33342 (D and F), and daunorubicin (E) assays (Supplementary Figure 3 A$\mathrm{F})$; concentration-effect curves of compound 26 against $\mathrm{ABCB} 1$ ( $\mathrm{A}$ and $\mathrm{D}$ ), $\mathrm{ABCC} 1$ (B and $\mathrm{E}$ ), and ABCG2 (C and $F$ ) as determined in calcein $A M$ ( $A$ and $B$ ), pheophorbide A (C), Hoechst 33342 (D and F), and daunorubicin (E) assays (Supplementary Figure 4 AF); and LC-MS data of compounds 11-33 as provided by ENAMINE (PDF)

\section{AUTHOR INFORMATION}

\section{Corresponding Author}

Sven Marcel Stefan - Department of Neuro-/Pathology, University of Oslo and Oslo University Hospital, 0372 Oslo, Norway; Department of Pharmaceutical and Cellbiological Chemistry, Pharmaceutical Institute, University of Bonn, 53121 Bonn, Germany; Cancer Drug Resistance and Stem Cell Program, University of Sydney, Sydney, New South Wales 2065, Australia; @ orcid.org/0000-0002-2048-8598; Email: s.m.stefan@medisin.uio.no

\section{Authors}

Vigneshwaran Namasivayam - Department of Pharmaceutical and Cellbiological Chemistry, Pharmaceutical Institute, University of Bonn, 53121 Bonn, Germany; ○ orcid.org/0000-0003-3031-3377

Katja Silbermann - Department of Pharmaceutical and Cellbiological Chemistry, Pharmaceutical Institute, University of Bonn, 53121 Bonn, Germany; 이이.org/0000-0002$8546-5290$
Michael Wiese - Department of Pharmaceutical and Cellbiological Chemistry, Pharmaceutical Institute, University of Bonn, 53121 Bonn, Germany; (i) orcid.org/0000-00025851-5336

Jens Pahnke - Department of Neuro-/Pathology, University of Oslo and Oslo University Hospital, 0372 Oslo, Norway; LIED, University of Lübeck, 23538 Lübeck, Germany; Department of Pharmacology, Faculty of Medicine, University of Latvia, 1004 Riga, Latvia; Department of Bioorganic Chemistry, Leibniz-Institute of Plant Biochemistry, 06120 Halle, Germany; (1) orcid.org/0000-0001-7355-4213

Complete contact information is available at: https://pubs.acs.org/10.1021/acs.jmedchem.0c02199

\section{Notes}

The authors declare no competing financial interest.

\section{ACKNOWLEDGMENTS}

V.N. thanks ChemAxon for providing an academic license to their software. J.P. received funding from Deutsche Forschungsgemeinschaft/Germany (DFG, German Research Foundation; 252102222, 263024513); Ministerium für Wirtschaft und Wissenschaft Sachsen-Anhalt/Germany (ZS/2016/ 05/78617); Latvian Council of Science/Latvia (lzp-2018/10275); Nasjonalforeningen (16154), HelseSØ/Norway (2016062, 2019054, 2019055); Barnekreftforeningen (19008); EEA grant/Norway grants Kappa programme (TAČR TARIMAD TO100078); Norges forskningsrådet/ Norway (251290, 260786 PROP-AD, 295910 NAPI, and PETABC); European Commission (643417). PROP-AD and PETABC are EU Joint Programme - Neurodegenerative Disease Research (JPND) projects. PROP-AD is supported through the following funding organizations under the aegis of JPND - www.jpnd.eu (AKA \#301228 - Finland, BMBF \#01ED1605 - Germany, CSO-MOH \#30000-12631 - Israel, NFR \#260786 - Norway, SRC \#2015-06795 - Sweden). PETABC is supported through the following funding organizations under the aegis of JPND - www.jpnd.eu (NFR - Norway, FFR - Austria, BMBF - Germany, MSMR Czech Republic, VIAA - Latvia, ANF - France, and SRC Sweden). The projects receive funding from the European Union's Horizon 2020 research and innovation programme under grant agreement \#643417 (JPco-fuND). S.M.S. received a Walter Benjamin fellowship of the DFG [STE2931/2 (446812474)].

\section{ABBREVIATIONS USED}

$\mathrm{ABC}$, ATP-binding cassette; BCRP, breast cancer resistance protein; calcein AM, calcein acetoxymethyl; C@PA, computeraided pattern analysis; $\mathrm{EC}_{50}$, half-maximal reversal concentration; $\mathrm{IC}_{50}$, half-maximal inhibition concentration; $\mathrm{I}_{\max }$, maximal inhibition level; $\mathrm{I}_{\text {rel }}$, relative inhibition; $\log \mathrm{P}$, partition coefficient; MDR, multidrug resistance; MRP1, multidrug resistance-associated protein 1; MW, molecular weight; P-gp, P-glycoprotein; SMILES, simplified molecular input line entry specification; Tc, Tanimoto coefficient.

\section{REFERENCES}

(1) Pan, S.-T.; Li, Z.-L.; He, Z.-X.; Qiu, J.-X.; Zhou, S.-F. Molecular mechanisms for tumour resistance to chemotherapy. Clin. Exp. Pharmacol. Physiol. 2016, 43, 723-737. 
(2) Palmeira, A.; Sousa, E.; Vasconcelos, M. H.; Pinto, M. M. Three decades of P-gp inhibitors: skimming through several generations of scaffolds. Curr. Med. Chem. 2012, 19, 1946-2025.

(3) Stefan, S. M.; Wiese, M. Small-molecule inhibitors of multidrug resistance-associated protein 1 and related processes. A historic approach and recent advances. Med. Res. Rev. 2019, 39, 176-264.

(4) Peña-Solórzano, D.; Stark, S. A.; König, B.; Sierra, C. A.; OchoaPuentes, C. ABCG2/BCRP: specific and nonspecific modulators. Med. Res. Rev. 2017, 37, 987-1050.

(5) Amiri-Kordestani, L.; Basseville, A.; Kurdziel, K.; Fojo, A. T.; Bates, S. E. Targeting MDR in breast and lung cancer: discriminating its potential importance from the failure of drug resistance reversal studies. Drug. Resist. Updat. 2012, 15, 50-61.

(6) Stefan, S. M. Multi-target ABC transporter modulators: what next and where to go? Future Med. Chem. 2019, 11, 2353-2358.

(7) Sharom, F. J.; Tamaki, A.; Ierano, C.; Szakacz, G.; Robey, R. W.; Bates, S. E. The controversial role of $\mathrm{ABC}$ transporters in clinical oncology. Essay Biochem. 2011, 50, 209-232.

(8) Stefan, K.; Wen Leck, L. Y.; Namasivayam, V.; Bascuñana, P.; Huang, M. L.-H.; Riss, P. J.; Pahnke, J.; Jansson, P. J.; Stefan, S. M. Vesicular ATP-binding cassette transporters in human disease: relevant aspects of their organization for future drug development. Future Drug Discov. 2020, 2, FDD51.

(9) Robey, R. W.; Pluchino, K. M.; Hall, M. D.; Fojo, A. T.; Bates, S. E.; Gottesman, M. M. Revisiting the role of $\mathrm{ABC}$ transporters in multidrug-resistant cancer. Nat. Rev. Cancer 2018, 18, 452-464.

(10) Liu, B.; Li, L.-J.; Gong, X.; Zhang, W.; Zhang, H.; Zhao, L. Coexpression of ATP binding cassette transporters is associated with poor prognosis in acute myeloid leukemia. Oncol. Lett. 2018, 15, 6671-6677.

(11) Schumacher, T.; Krohn, M.; Hofrichter, J.; Lange, C.; Stenzel, J.; Steffen, J.; Dunkelmann, T.; Paarmann, K.; Fröhlich, C.; Uecker, A.; Plath, A. S.; Sommer, A.; Brüning, T.; Heinze, H. J.; Pahnke, J. $\mathrm{ABC}$ transporters $\mathrm{B} 1, \mathrm{C} 1$ and $\mathrm{G} 2$ differentially regulate neurodegeneration in mice. PLoS One 2012, 7, No. e35613.

(12) Bernstein, H. G.; Hölzl, G.; Dobrowolny, H.; Hildebrandt, J.; Trübner, K.; Krohn, M.; Bogerts, B.; Pahnke, J. Vascular and extravascular distribution of the ATP-binding cassette transporters $\mathrm{ABCB} 1$ and $\mathrm{ABCC} 1$ in aged human brain and pituitary. Mech. Ageing Dev. 2014, 141-142, 12-21.

(13) Samant, M. D.; Jackson, C. M.; Felix, C. L.; Jones, A. J.; Goodrich, D. W.; Foster, B. A.; Huss, W. J. Multi-Drug Resistance ABC Transporter Inhibition Enhances Murine Ventral Prostate Stem/ Progenitor Cell Differentiation. Stem Cells Dev. 2015, 24, 1236-1251.

(14) Silbermann, K.; Li, J.; Namasivayam, V.; Stefan, S. M.; Wiese, M. Rational drug design of 6-substituted 4-anilino-2-phenylpyrimidines for exploration of novel ABCG2 binding site. Eur. J. Med. Chem. 2020, 212, 113045.

(15) Silbermann, K.; Li, J.; Namasivayam, V.; Baltes, F.; Bendas, G.; Stefan, S. M.; Wiese, M. Superior pyrimidine derivatives as selective ABCG2 inhibitors and broad-spectrum $A B C B 1, A B C C 1$, and $A B C G 2$ antagonists. J. Med. Chem. 2020, 63, 10412-10432.

(16) Silbermann, K.; Stefan, S. M.; Elshawadfy, R.; Namasivayam, V.; Wiese, M. Identification of thienopyrimidine scaffold as inhibitor of the $\mathrm{ABC}$ transport protein $\mathrm{ABCC} 1$ (MRP1) and related transporters using a combined virtual screening approach. J. Med. Chem. 2019, 62, 4383-4400.

(17) Stefan, K.; Schmitt, S. M.; Wiese, M. 9-Deazapurines as broadspectrum inhibitors of the $\mathrm{ABC}$ transport proteins P-glycoprotein, multidrug resistance-associated protein 1 , and breast cancer resistance protein. J. Med. Chem. 2017, 60, 8758-8780.

(18) Ahmed-Belkacem, A.; Pozza, A.; Macalou, S.; Perez-Victoria, J. M.; Boumendjel, A.; Di Pietro, A. Inhibitors of cancer cell multidrug resistance mediated by breast cancer resistance protein (BCRP/ ABCG2). Anti-Cancer Drugs 2006, 17, 239-243.

(19) Ranjbar, S.; Khonkarn, R.; Moreno, A.; Baubichon-Cortay, H.; Miri, R.; Khoshneviszadeh, M.; Saso, L.; Edraki, N.; Falson, P.; Firuzi, O. 5-Oxo-hexahydroquinoline derivatives as modulators of P-gp,
MRP1 and BCRP transporters to overcome multidrug resistance in cancer cells. Toxicol. Appl. Pharmacol. 2019, 362, 136-149.

(20) Contino, M.; Guglielmo, S.; Perrone, M. G.; Giampietro, R.; Rolando, B.; Carrieri, A.; Zaccaria, D.; Chegaev, K.; Borio, V.; Riganti, C.; Zabielska-Koczywąs, K.; Colabufo, N. A.; Fruttero, R. New tetrahydroisoquinoline-based P-glycoprotein modulators: decoration of the biphenyl core gives selective ligands. Med. Chem. Comm. 2018, 9, 862-869.

(21) Colabufo, N. A.; Contino, M.; Cantore, M.; Capparelli, E.; Perrone, M. G.; Cassano, G.; Gasparre, G.; Leopoldo, M.; Berardi, F.; Perrone, R. Naphthalenyl derivatives for hitting P-gp/MRP1/BCRP transporters. Bioorg. Med. Chem. 2013, 21, 1324-1332.

(22) Colabufo, N. A.; Berardi, F.; Perrone, M. G.; Cantore, M.; Contino, M.; Inglese, C.; Niso, M.; Perrone, R. Multi-drug-resistancereverting agents: 2 -aryloxazole and 2-arylthiazole derivatives as potent BCRP and MRP1 inhibitors. ChemMedChem 2009, 4, 188-195.

(23) Antoni, F.; Wifling, D.; Bernhardt, G. Water-soluble inhibitors of ABCG2 (BCRP) - A fragment-based and computational approach. Eur. J. Med. Chem. 2021, 210, 112958.

(24) Schmitt, S. M.; Stefan, K.; Wiese, M. Pyrrolopyrimidine derivatives and purine analogs as novel activators of multidrug resistance-associated protein 1 (MRP1, ABCC1). Biochim. Biophys. Acta, Biomembr. 2017, 1859, 69-79.

(25) Antoni, F.; Bause, M.; Scholler, M.; Bauer, S.; Stark, S. A.; Jackson, S. M.; Manolaridis, I.; Locher, K. P.; König, B.; Buschauer, A.; Bernhardt, G. Tariquidar-related triazoles as potent, selective and stable inhibitors of ABCG2 (BCRP). Eur. J. Med. Chem 2020, 191, 112133.

(26) Teodori, E.; Contino, M.; Riganti, C.; Bartolucci, G.; Braconi, L.; Manetti, D.; Manetti, M. N.; Trezza, A.; Athanasios, A.; Spiga, O.; Perrone, M. G.; Giampietro, R.; Gazzano, E.; Salerno, M.; Colabufo, N. A.; Dei, S. Design, synthesis and biological evaluation of stereoand regioisomers of amino aryl esters as multidrug resistance (MDR) reversers. Eur. J. Med. Chem. 2019, 182, 111655.

(27) Krapf, M. K.; Gallus, J.; Spindler, A.; Wiese, M. Synthesis and biological evaluation of quinazoline derivatives - A SAR study of novel inhibitors of ABCG2. Eur. J. Med. Chem. 2019, 161, 506-525.

(28) Krapf, M. K.; Gallus, J.; Wiese, M. Synthesis and biological investigation of 2,4-substituted quinazolines as highly potent inhibitors of breast cancer resistance protein (ABCG2). Eur. J. Med. Chem. 2017, 139, 587-611.

(29) Krapf, M. K.; Wiese, M. Synthesis and biological evaluation of 4-anilino-quinazolines and -quinolines as inhibitors of breast cancer resistance protein (ABCG2). J. Med. Chem. 2016, 59, 5449-5461.

(30) Mathias, T. J.; Natarajan, K.; Shukla, S.; Doshi, K. A.; Singh, Z. N.; Ambudkar, S. V.; Baer, M. R. The FLT3 and PDGFR inhibitor crenolanib is a substrate of the multidrug resistance protein $A B C B 1$ but does not inhibit transport function at pharmacologically relevant concentrations. Invest. New Drugs 2015, 33, 300-309.

(31) Hu, J.; Zhang, X.; Wang, F.; Wang, X.; Yang, K.; Xu, M.; To, K. K. W.; Li, Q.; Fu, L. Effect of ceritinib (LDK378) on enhancement of chemotherapeutic agents in $\mathrm{ABCB} 1$ and $\mathrm{ABCG} 2$ overexpressing cells in vitro and in vivo. Oncotarget 2015, 6, 44643-44659.

(32) Krauze, A.; Grinberga, S.; Krasnova, L.; Adlere, I.; Sokolova, E.; Domracheva, I.; Shestakova, I.; Andzans, Z.; Duburs, G. Thieno[2,3b]pyridines-a new class of multidrug resistance (MDR) modulators. Bioorg. Med. Chem. 2014, 22, 5860-5870.

(33) Juvale, K.; Gallus, J.; Wiese, M. Investigation of quinazolines as inhibitors of breast cancer resistance protein (ABCG2). Bioorg. Med. Chem. 2013, 21, 7858-7873.

(34) Juvale, K.; Stefan, K.; Wiese, M. Synthesis and biological evaluation of flavones and benzoflavones as inhibitors of BCRP/ ABCG2. Eur. J. Med. Chem. 2013, 67, 115-126.

(35) Mi, Y.-J.; Liang, Y.-J.; Huang, H.-B.; Zhao, H.-Y.; Wu, C.-P.; Wang, F.; Tao, L.-Y.; Zhang, C.-Z.; Dai, C.-L.; Tiwari, A. K.; Ma, X.X.; To, K. K. W.; Ambudkar, S. V.; Chen, Z.-S.; Fu, L.-W. Apatinib (YN968D1) reverses multidrug resistance by inhibiting the efflux function of multiple ATP-binding cassette transporters. Cancer Res. 2010, 70, 7981-7991. 
(36) Pick, A.; Klinkhammer, W.; Wiese, M. Specific inhibitors of the breast cancer resistance protein (BCRP). ChemMedChem 2010, 5, $1498-1505$.

(37) Ma, S.-L.; Hu, Y.-P.; Wang, F.; Huang, Z.-C.; Chen, Y.-F.; Wang, X.-K.; Fu, L.-W. Lapatinib antagonizes multidrug resistanceassociated protein 1 -mediated multidrug resistance by inhibiting its transport function. Mol. Med. 2014, 20, 390-399.

(38) Dai, C.-L.; Tiwari, A.-K.; Wu, C.-P.; Su, X.-D.; Wang, S.-R.; Liu, D.-G.; Ashby, C. R., Jr.; Huang, Y.; Robey, R. W.; Liang, Y.-J.; Chen, L.-M.; Shi, C.-J.; Ambudkar, S. V.; Chen, Z.-S.; Fu, L.-W. Lapatinib (Tykerb, GW572016) reverses multidrug resistance in cancer cells by inhibiting the activity of ATP-binding cassette subfamily B member 1 and G member 2. Cancer Res. 2008, 68, 7905-7914.

(39) Colabufo, N. A.; Pagliarulo, V.; Berardi, F.; Contino, M.; Inglese, C.; Niso, M.; Ancona, P.; Albo, G.; Pagliarulo, A.; Perrone, R. Bicalutamide failure in prostate cancer treatment: involvement of multi drug resistance proteins. Eur. J. Pharmacol. 2008, 601, 38-42.

(40) Ivnitski-Steele, I.; Larson, R. S.; Lovato, D. M.; Khawaja, H. M.; Winter, S. S.; Oprea, T. I.; Sklar, L. A.; Edwards, B. S. Highthroughput flow cytometry to detect selective inhibitors of ABCB1, ABCC1, and ABCG2 transporters. Assay Drug Dev. Technol. 2008, 6, 263-276.

(41) Pawarode, A.; Shukla, S.; Minderman, H.; Fricke, S. M.; Pinder, E. M.; O'Loughlin, K. L.; Ambudkar, S. V.; Baer, M. R. Differential effects of the immunosuppressive agents cyclosporin $\mathrm{A}$, tacrolimus and sirolimus on drug transport by multidrug resistance proteins. Cancer Chemother. Pharmacol. 2007, 60, 179-188.

(42) Özvegy-Laczka, C.; Hegedűs, T.; Varady, G.; Ujhelly, O.; Schuetz, J. D.; Váradi, A.; Kéri, G.; Őrfi, L.; Német, K.; Sarkadi, B. High-affinity interaction of tyrosine kinase inhibitors with the ABCG2 multidrug transporter. Mol. Pharmacol. 2004, 65, 1485-1495.

(43) Demel, M. A.; Schwaha, R.; Krämer, O.; Ettmayer, P.; Haaksma, E. E.; Ecker, G. F. In silico prediction of substrate properties for ABC-multidrug transporters. Expert Opin. Drug Metab. Toxicol. 2008, 4, 1167-1180.

(44) Demel, M. A.; Krämer, O.; Ettmayer, P.; Haaksma, E. E.; Ecker, G. F. Predicting ligand interactions with $\mathrm{ABC}$ transporters in ADME. Chem. Biodivers. 2009, 6, 1960-1969.

(45) Wise, J. G.; Nanayakkara, A. K.; Aljowni, M.; Chen, G.; De Oliveira, M. C.; Ammerman, L.; Olengue, K.; Lippert, A. R.; Vogel, P. D. Optimizing targeted inhibitors of P-glycoprotein using computational and structure-guided approaches. J. Med. Chem. 2019, 62, $10645-10663$.

(46) Broccatelli, F.; Carosati, E.; Neri, A.; Frosini, M.; Goracci, L.; Oprea, T. I.; Cruciani, G. A novel approach for predicting Pglycoprotein $(\mathrm{ABCB} 1)$ inhibition using molecular interaction fields. J. Med. Chem. 2011, 54, 1740-1751.

(47) Jiang, D.; Lei, T.; Wang, Z.; Shen, C.; Cao, D.; Hou, T. ADMET evaluation in drug discovery. 20. Prediction of breast cancer resistance protein inhibition through machine learning. Aust. J. Chem. 2020, 12, 16.

(48) Clark, A. M.; Labute, P. Detection and assignment of common scaffolds in project databases of lead molecules. J. Med. Chem. 2009, $52,469-483$.

(49) Molecular Operating Environment (MOE), version 2019.01; Chemical Computing Group: Montreal, Quebec, Canada.

(50) Jordan, A. M.; Roughley, S. D. Drug discovery chemistry: a primer for the non-specialist. Drug Discovery Today 2009, 14, 731744.

(51) InstantJChem, version 20.15.0; ChemAxon, Budapest, Hungary. (52) ENAMINE ${ }^{\circledR}$ Diverse REAL Drug-like Compound Library, Riga, Latvia. https://enamine.net/library-synthesis/real-compounds/realcompound-libraries.

(53) Wang, S.; Wan, N. C.; Harrison, J.; Miller, W.; Chuckowree, I.; Sohal, S.; Hancox, T. C.; Baker, S.; Folkes, A.; Wilson, F.; Thompson, D.; Cocks, S.; Farmer, H.; Boyce, A.; Freathy, C.; Broadbridge, J.; Scott, J.; Depledge, P.; Faint, R.; Mistry, P.; Charlton, P. Design and synthesis of new templates derived from pyrrolopyrimidine as selective multidrug-resistance-associated protein inhibitors in multidrug resistance. J. Med. Chem. 2004, 47, 1339-1350.

(54) Wang, S.; Folkes, A.; Chukowree, I.; Cockcroft, X.; Sohal, S.; Miller, W.; Milton, J.; Wren, S. P.; Vicker, N.; Depledge, P.; Scott, J.; Smith, L.; Jones, H.; Mistry, P.; Faint, R.; Thompson, D.; Cocks, S. Studies on pyrrolopyrimidines as selective inhibitors of multidrugresistance-associated protein in multidrug resistance. J. Med. Chem. 2004, 47, 1329-1338.

(55) Schmitt, S. M.; Stefan, K.; Wiese, M. Pyrrolopyrimidine Derivatives as Novel Inhibitors of Multidrug Resistance-Associated Protein 1 (MRP1, ABCC1). J. Med. Chem. 2016, 59, 3018-3033.

(56) Silbermann, K.; Shah, C. P.; Sahu, N. U.; Juvale, K.; Stefan, S. M.; Kharkar, P. S.; Wiese, M. Novel chalcone and flavone derivatives as selective and dual inhibitors of the transport proteins $\mathrm{ABCB} 1$ and ABCG2. Eur. J. Med. Chem. 2019, 164, 193-213.

(57) Müller, H.; Klinkhammer, W.; Globisch, C.; Kassack, M. U.; Pajeva, I. K.; Wiese, M. New functional assay of P-glycoprotein activity using Hoechst 33342. Bioorg. Med. Chem. 2007, 15, 74707470.

(58) Suillerot, A. G.; Gueye, C. M.; Salerno, M.; Loetchutinat, C.; Fokt, I.; Krawszyk, M.; Kowalczyk, T.; Priebe, W. Analysis of drug transport kinetics in multidrug-resistant cells: implications for drug action. Curr. Med. Chem. 2001, 8, 51-64.

(59) Ren, Z.; Gu, X.; Lu, B.; Chen, Y.; Chen, G.; Feng, J.; Lin, J.; Zhang, Y.; Peng, H. Anticancer efficacy of a nitric oxide-modified derivative of bifendate against multidrug-resistant cancer cells. J. Cell Mol. Med. 2016, 20, 1095-1105.

(60) Guglielmo, S.; Lazzarato, L.; Contino, M.; Perrone, M. G.; Chegaev, K.; Carrieri, A.; Fruttero, R.; Colabufo, N. A.; Gasco, A. Structure-Activity Relationship Studies on Tetrahydroisoquinoline Derivatives: [4'-(6,7-Dimethoxy-3,4-dihydro-1H-isoquinolin-2ylmethyl)biphenyl-4-ol] (MC70) Conjugated through Flexible Alkyl Chains with Furazan Moieties Gives Rise to Potent and Selective Ligands of P-glycoprotein. J. Med. Chem. 2016, 59, 6729-6738.

(61) Obreque-Balboa, J. E.; Sun, Q.; Bernhardt, G.; König, B.; Buschauer, A. Flavonoid derivatives as selective $\mathrm{ABCC} 1$ modulators: synthesis and functional characterization. Eur. J. Med. Chem. 2016, $109,124-133$.

(62) Fruttero, R.; Cosetti, M.; Chegaev, K.; Guglielmo, S.; Gasco, A.; Berardi, F.; Niso, M.; Perrone, R.; Panaro, M. A.; Colabufo, N. A. Phenylsulfonylfuroxans as Modulators of Multidrug-ResistanceAssociated Protein-1 and P-Glycoprotein. J. Med. Chem. 2010, 53, $5467-5475$

(63) Wu, C.-P.; Lusvarghi, S.; Wang, J.-C.; Hsiao, S.-H.; Huang, Y.H.; Hung, T.-H.; Ambudkar, S. V. The selective class IIa histone deacetylase inhibitor TMP195 resensitizes ABCB1- and ABCG2overexpressing multidrug-resistant cancer cells to cytotoxic anticancer drugs. Int. J. Mol. Sci. 2019, 21, 238.

(64) Ascione, A.; Cianfriglia, M.; Dupuis, M. L.; Mallano, A.; Sau, A.; Tregno, F. P.; Pezzola, S.; Caccuri, A. M. The glutathione Stransferase inhibitor 6-(7-nitro-2,1,3-benzoxadiazol-4-ylthio)hexanol overcomes the MDR1-P-glycoprotein and MRP1-mediated multidrug resistance in acute myeloid leukemia cells. Cancer Chemother. Pharmacol. 2009, 64, 419-424.

(65) Köhler, S. C.; Vahdati, S.; Scholz, M. S.; Wiese, M. Structure activity relationships, multidrug resistance reversal and selectivity of heteroarylphenyl ABCG2 inhibitors. Eur. J. Med. Chem. 2018, 146, 483-500.

(66) Gozzi, G. J.; Pires, A. D. R. A.; Valdameri, G.; Rocha, M. E. M.; Martinez, G. R.; Noleto, G. R.; Acco, A.; de Souza, C. E. A.; Echevarria, A.; Dos Reis, C. M.; Di Pietro, A.; Cadena, S. M. S. C. Selective cytotoxicity of 1,3,4-thiadiazolium mesoionic derivatives on hepatocarcinoma cells (HepG2). PLoS One 2015, 10, No. e0130046.

(67) Irwin, J. J.; Raushel, F. M.; Shoichet, B. K. Virtual screening against metalloenzymes for inhibitors and substrates. Biochemistry 2005, 44, 12316-12328.

(68) Carlsson, J.; Yoo, L.; Gao, Z.-G.; Irwin, J. J.; Shoichet, B. K.; Jacobson, K. A. Structure-based discovery of $\mathrm{A}_{2 \mathrm{~A}}$ Adenosine Receptor Ligands. J. Med. Chem. 2010, 53, 3748-3755. 
(69) Mysinger, M. M.; Weiss, D. R.; Ziarek, J. J.; Gravel, S.; Doak, A. K.; Karpiak, J.; Heveker, N.; Shoichet, B. K.; Volkman, B. F. Structurebased ligand discovery for the protein-protein interface of chemokine receptor CXCR4. Proc. Natl. Acad. Sci. U. S. A. 2012, 109, 55175522.

(70) Ripphausen, P.; Freundlieb, M.; Brunschweiger, A.; Zimmermann, H.; Müller, C. E.; Bajorath, J. Virtual screening identifies novel sulfonamide inhibitors of ecto-5' -nucleotidase. J. Med. Chem. 2012, 55, 6576-6581.

(71) Gunera, J.; Baker, J. G.; van Hilten, N.; Rosenbaum, D. M.; Kolb, P. Structure-based discovery of novel ligands for the orexin 2 receptor. J. Med. Chem. 2020, 63, 11045-11053.

(72) National Center for Biotechnological Information, U. S. National Library of Medicine (2020) 8600 Rockville Pike, Bethesda MD, 20894 USA.

(73) Baell, J. B.; Holloway, G. A. New substructure filters for removal of pan assay interference compounds (PAINS) from screening libraries and for their exclusion in bioassays. J. Med. Chem. 2010, 53, 2719-2740.

(74) Pavek, P.; Merino, G.; Wagenaar, E.; Bolscher, E.; Novotna, M.; Jonker, J. W.; Schinkel, A. H. Human breast cancer resistance protein: interactions with steroid drugs, hormones, the dietary carcinogen 2amino-1-methyl-6-phenylimidazo(4,5-b)pyridine, and transport of cimetidine. J. Pharmacol. Exp. Ther. 2005, 312, 144-152. 